\title{
An overview of the microphysical structure of cirrus clouds observed during EMERALD-1
}

\author{
By M. W. GALLAGHER*1, P. J. CONNOLLY ${ }^{1}$, J. WHITEWAY ${ }^{2}$, D. FIGUERAS-NIETO ${ }^{1}$, M. FLYNN, ${ }^{1}$ \\ T. W. CHOULARTON ${ }^{1}$, K. N. BOWER ${ }^{1}$, C. COOK $^{2}$, R. BUSEN ${ }^{3}$ and J. HACKER ${ }^{4}$ \\ ${ }^{1}$ University of Manchester Institute of Science and Technology Physics Department, UK \\ ${ }^{2}$ University of Wales Physics Department, Aberystwyth, UK \\ ${ }^{3}$ Deutsches Zentrum für Luft-und Raumfart, Oberpfaffenhofen, Germany \\ ${ }^{4}$ Airborne Research Australia, Flinders, Adelaide, Australia
}

(Received 31 July 2003; revised 19 May 2004)

\begin{abstract}
SUMMARY
High-resolution ice microphysical, turbulence, heat and water vapour flux data in cirrus clouds were collected by the Airborne Research Australia's (ARA) Egret Grob 520T research aircraft during the first Egret Microphysics with Extended Radiation and Lidar experiment (EMERALD-1). The in situ cirrus measurements were guided by simultaneous airborne lidar measurements collected by the ARA Super King Air research aircraft which flew below the cirrus and whose horizontal position was synchronized with the Egret. This allowed the microphysics and turbulence measurements to be interpreted and evaluated within the context of large-scale cirrus structure and its evolution. A significant feature of the clouds observed was the presence on occasion of active convective columns. Large variations in the cirrus dynamics were observed, with significant variations in the ice crystal habit from cloud top to cloud base and within the evaporating fall-streaks of precipitation. However, on average the picture presented is consistent with that shown by Heymsfield and Miloshevich, and by Kajikawa and Heymsfield, with the upper supersaturated region of the cloud acting as an active particle-generation zone where homogeneous nucleation proceeds apace; ice crystals there are initially dominated by small irregular or spheroidally shaped particles, some of which can be identified as proto or 'germ' rosettes. These are then observed to grow into more open bullet rosette and columnar types as they fall into the less supersaturated middle and lower layers of the cloud. The mean recognisable ice particle size fell within a very narrow size band, 70-90 $\mu \mathrm{m}$, but the actual size distribution is thought to increase in a continuous manner to smaller sizes. However, there are currently instrument limitations that make it difficult to confirm this unambiguously. Unlike most previous studies, however, the cirrus clouds observed here were mostly devoid of pristine plate-like crystals, as nucleation and growth within the planar growth regime was rarely encountered. During some cases bullet rosettes, once formed, did undergo transition to the plate growth regime with complex crystal shapes resulting. The mean size of pristine bullet rosettes was again confined to a relatively narrow range. The likely nucleation processes dominating in cirrus clouds are discussed in the light of the observations.

Very high concentrations of small ice crystals were sometimes detected, concentrations reaching a maximum of $10000 \mathrm{~L}^{-1}$. There is strong evidence supporting these high concentrations which are probably produced by the homogeneous freezing of aerosol.
\end{abstract}

Keywords: Aircraft Climate Concentration Habit Ice-size distribution Microphysics

\section{INTRODUCTION}

Cirrus clouds have an important influence on climate, and any changes to their properties will have important consequences for climate change (Mitchell et al. 1989). It is important, therefore, to obtain information on their microphysical structures and the processes controlling the structure of these clouds. A number of field projects over the last 20 years have been dedicated to understanding the properties of these clouds, e.g. the First ISCCP $\dagger$ Field Experiments (FIRE) 1 and FIRE 2, and CRYSTAL-FACE (the Cirrus Regional Study of Tropical Anvils and Cirrus Layers-Florida Area Cirrus Experiment). For an overview of these projects see Lynch et al. (2002). Heymsfield (1972, 1986) and Stephens et al. (1990) have done much work on the characterization of cirrus cloud microphysics. From these studies and other related work it has been

\footnotetext{
* Corresponding author: University of Manchester, Atmospheric Physics Group, School of Earth Atmospheric and Environmental Sciences, Sackville Street Building, Sackville Street, Manchester M60 1QD, UK.

e-mail: martin.gallagher@manchester.ac.uk

† International Satellite Cloud Climatology Project.

(c) Royal Meteorological Society, 2005.
} 
shown that a wide range of ice crystal concentrations of typically 50 to $500 \mathrm{~L}^{-1}$ are present. Further, ice crystal habits can vary widely with thick plates and columns, bullets and bullet rosettes, together with aggregates, present. The extensive data gathered have enabled parametrizations of cirrus cloud crystal size and ice-water content to be derived. Sassen (1985) observed highly supercooled water in cirrus clouds, whilst Heymsfield and Miloshevic (1995) measured supercooled water droplets in small quantities down to -33 and $-36{ }^{\circ} \mathrm{C}$ within orographic cirrus; in deep convective clouds Rosenfield and Woodley (2000) observed sustained supercooled liquid water down to $-37.5^{\circ} \mathrm{C}$. These observations have consequences for ice formation processes in these clouds. There is still much uncertainty, however, in attempting to relate observed atmospheric ice crystal growth habits, and the nucleation processes leading to those habits, to those predicted and observed in controlled laboratory conditions.

The EMERALD-1 (Egret Microphysics with Extended Radiation and Lidar) field experiment was designed to investigate detailed multi-scale ice microphysical structure and the dynamics of glaciated cirrus clouds by combining in situ and remote sensing airborne instruments and methodologies. The aim was to use these observations to explore how the dynamical structure of cirrus clouds is coupled with their ice microphysical structure and radiative properties, and how this may govern their subsequent evolution. The unique feature of this experiment is the bringing together of simultaneous Lidar, dynamical and high quality in situ microphysical data.

In this paper we present a broad overview of the EMERALD-1 microphysical database, and a description of some of the mean cirrus properties encountered, as a prelude to more detailed examinations of individual case-studies. The EMERALD-1 cirrus database currently consists of observations of ten midlatitude cirrus clouds between latitudes 32 and $40^{\circ} \mathrm{S}$, and longitudes 130 to $142^{\circ} \mathrm{E}$. The clouds encountered were dominated by small irregular or spheroidal ice crystals, but with regions where growth of large bullet rosettes was commonly observed. In addition, localized regions of water saturation were frequently detected particularly near the cloud base.

The average variation of the shape-sensitive ice crystal aspect-ratio, $A_{\mathrm{r}}$, is used to investigate ice crystal growth regimes, using cloud particle imager (CPI Model 230) data as a function of cloud temperature based on the ten flights. Parametrizations of $A_{\mathrm{r}}$ are then compared with previous datasets. A picture of the mean vertical ice microphysical structure is presented to illustrate the evolution of these parameters. Finally, the typical turbulent vertical velocity variations, $w^{\prime}$, and relative humidity with respect to ice, $R H_{\text {ice }}$, are used to discuss time-scales for ice crystal growth and evolution within these clouds. Further detailed investigations of individual EMERALD case-studies with some new findings will be presented in subsequent papers.

\section{THE EMERALD-1 FIELD EXPERIMENT}

The EMERALD-1 field experiment was conducted from Flinders Field near Adelaide in South Australia between 5 and 27 September 2001. The period of the experiment was limited to generally west to south-west frontal flow towards the continent, where high-altitude cirrus formation was commonly observed with cloud base levels varying between 6 and $10 \mathrm{~km}$ and cloud tops from 8 to $12 \mathrm{~km}$. Figure 1(a) is the surface chart for 1800 UTC 19 September, showing synoptic conditions typical for this period with the passage of a low-pressure region and associated cold front towards New South Wales and Tasmania. The slow moving cold front had merged from two separate cold fronts with a further low situated across the Port Hedland area. Figure 1(b) is the concurrent infrared satellite image that highlights the extensive frontal cirrus layer over much of the 
region, which was subsequently investigated. The inset map shows the flight path of the aircraft on 19 September, which was centred close to Kangaroo Island. Figure 1(c), is the temperature and relative-humidity sounding measured by aircraft on this day, which shows an almost constant lapse rate of $7.2 \mathrm{degC} \mathrm{km}^{-1}$. This was typical of the majority of the flights.

The experimental approach adopted for EMERALD-1 essentially consisted of flying two aircraft in tandem in a box pattern. The lower aircraft, the Airborne Research Australia's (ARA) instrumented Super King Air, maintained a constant altitude below cloud, at around $7 \mathrm{~km}$, and directed a second aircraft in real-time to undertake stepped profiles through regions of interest. The horizontal range between the two aircraft varied from 1-2 km on average. These regions were identified by means of a cloud lidar mounted on board the King Air. The second aircraft was the ARA Grob 520T highaltitude research aircraft, which was instrumented for cloud microphysics, turbulence and trace-gas measurements. Where possible the two aircraft locations were synchronized so that the highest flying aircraft was always directly above the lower one. The methodology and instrumentation is described in more detail by Whiteway et al. (2002).

Thirteen Egret flights were conducted during EMERALD-1, and each flight is referred to hereafter as EMXX where XX is the flight number. A typical experimental flight path is shown in Fig. 2, again for the 19 September, which is flight EM09. This shows the total lidar returned power recorded by the King Air, which reveals the two dimensional (2D) structure of the cloud. Also shown is the directed in-cloud flight path of the Egret aircraft together with images of typical ice crystal types observed at different points along the flight track where the aircraft penetrated cloud. The lower section of Fig. 2 shows the temperature and relative humidity observed during the penetrations.

\section{INSTRUMENTATION}

The instrumentation and research capabilities of the ARA Egret and King Air aircraft are described in detail by Hacker and Crawford (1999). In this paper we focus on the microphysical instrumentation deployed to measure ice particle-size distribution and habit classification, with supporting measurements of turbulence, temperature, and relative humidities with respect to water, $R H$, and with respect to ice, $R H_{\text {ice. }}$.

Cloud ice microphysical characteristics were measured using the 'Lawson' CPI (Model 230) described by Lawson and Cormack (1995), Lawson and Jensen (1998) and Lawson et al. (1998). The performance of these and similar imaging probes is discussed by Korolev et al. (1999a) and Lawson et al. (2001). A Droplet Measurement Technologies Particle Measuring Systems (PMS) Forward Scattering Spectrometer Probe (FSSP-100), was used to measure small ice particle and droplet concentrations. This instrument is an upgraded version of the standard PMS FSSP-100, originally described by Knollenberg (1981), the operation of which is assessed in detail by Baumgardner (1985) and others. The accuracy of the FSSP-100 and the various problems associated with the reliance on Mie scattering theory by such instruments for small ice particles has been discussed recently in the literature. These problems do not appear to manifest themselves when the instrument is operated in cirrus with high concentrations of small ice particles present, as described by Lawson et al. (2001). We present a brief evaluation of the counting and sizing performance of the microphysical instruments.

$R H_{\text {ice }}$, and $R H$ were determined from measurements of temperature, dew point and ice point using a Buck Research CR-2 Ice Point Hygrometer with an accuracy of $\pm 0.1 \mathrm{degC}$ and response time of $1 \mathrm{~s}$. 
(a)

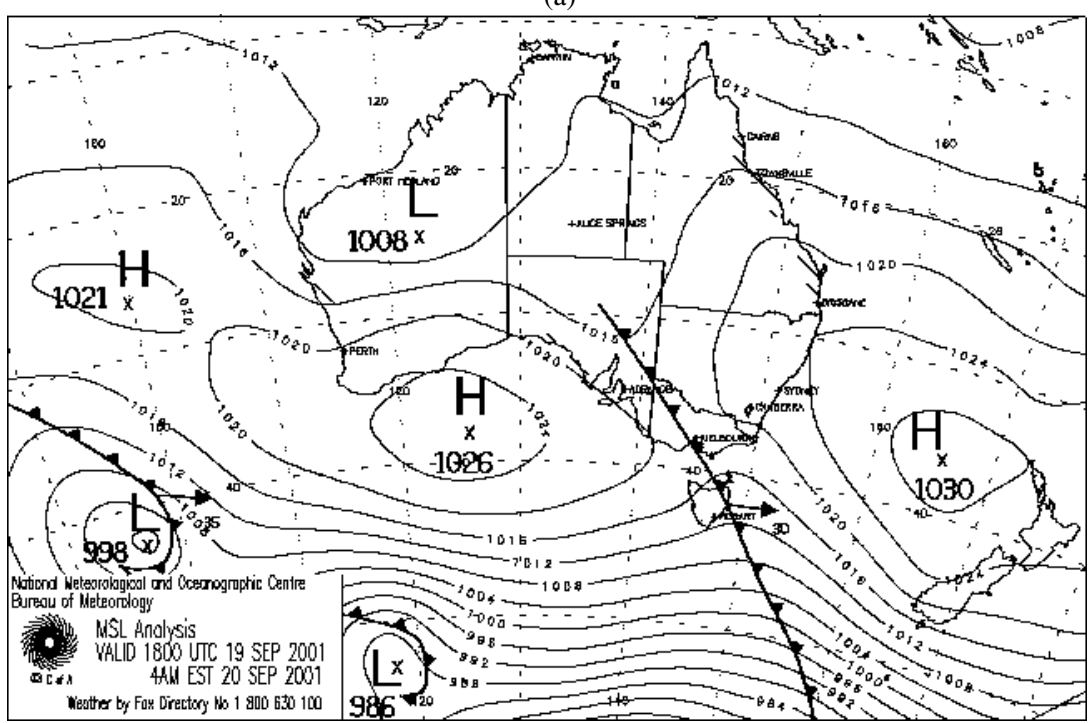

(b)

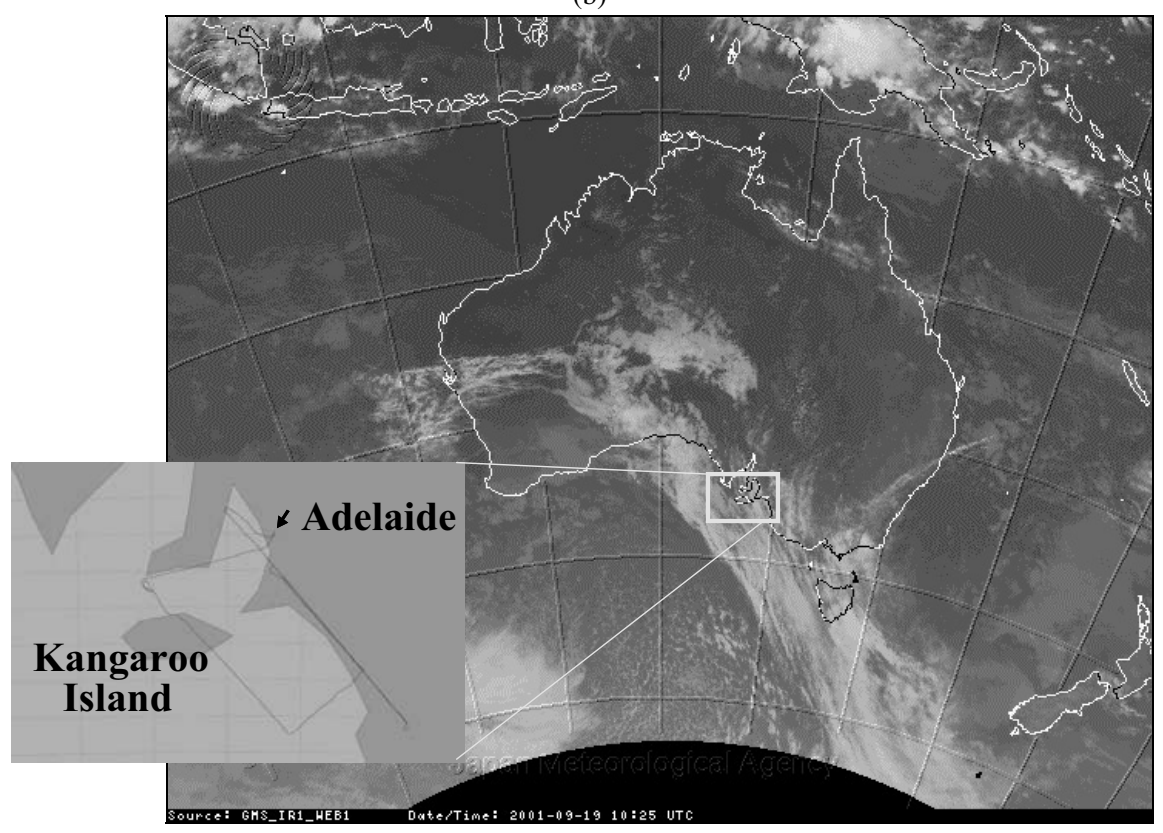

Figure 1. (a) Synoptic chart for 1800 UTC 19 September 2001; (b) Infrared satellite image for 19 September 2001 - the inset shows a typical flight track within the investigation area; (c) typical temperature (near-straight line) and relative-humidity profiles recorded by the ARA Egret aircraft during EMERALD-1 (flight EM09, 19 September 2001). ((a) and (b) are by courtesy of the Australian Bureau of Meteorology.) See text for further details. 


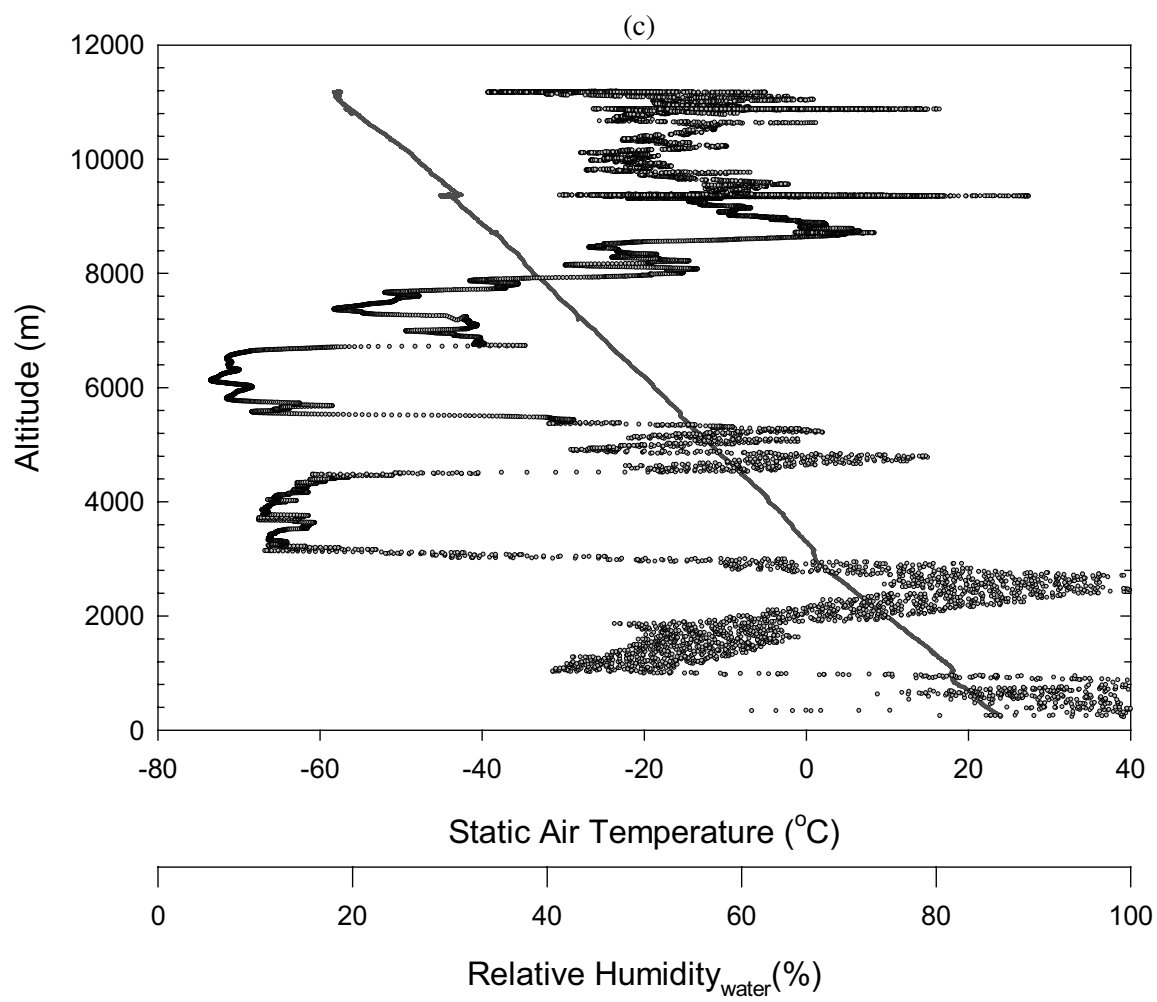

Figure 1. Continued.

Turbulent velocity fluctuations in 3D were measured using the 'Best Atmospheric Turbulence' probe developed jointly by NOAA/ATDL (National Oceanic and Atmospheric Administration/Army Doctrine and Training Digital Library), Flinders University Australia and Airborne Research Australia (Hacker and Crawford 1999). This sensor utilizes digital global positioning satellite data to recover attitude information with a response of $50 \mathrm{~Hz}$, accurate to $0.5 \mathrm{~m}$ and $0.05^{\circ}$. Coupled with the nine-hole pressure sensor, 3D turbulence information can be output in real-earth coordinates with an accuracy of $\pm 2.0 \mathrm{~cm} \mathrm{~s}^{-1}$. The probe also provides temperature measurements via a micro-bead thermistor with a response time of $0.07 \mathrm{~s}$.

\section{(a) Microphysics instrumentation: cloud particle imager}

The CPI instrument is described in detail by Lawson et al. (1998). This instrument couples an innovative dual laser beam particle detection system (pds) that is aligned nearly coplanar with the imaging plane, and triggers a $25 \mathrm{~ns}$ pulsed laser diode that subsequently casts an image of the particle passing through the pds onto a solid-state charged couple device (CCD) sensor. The CCD is a one megapixel device, each pixel having a resolution of typically $2.3 \mu \mathrm{m}$. This effectively yields a minimum 'resolvable' particle image of about $10 \mu \mathrm{m}$ across. The maximum object dimension that can be located within the image plane is thus about $2.3 \mathrm{~mm}$. The sensor is typically run at sampling rates from 20 to $40 \mathrm{~Hz}$. The output from the CCD is linked to a video image-processing engine capable of recording images with 256 grey-scale levels and 
Realtive humidity
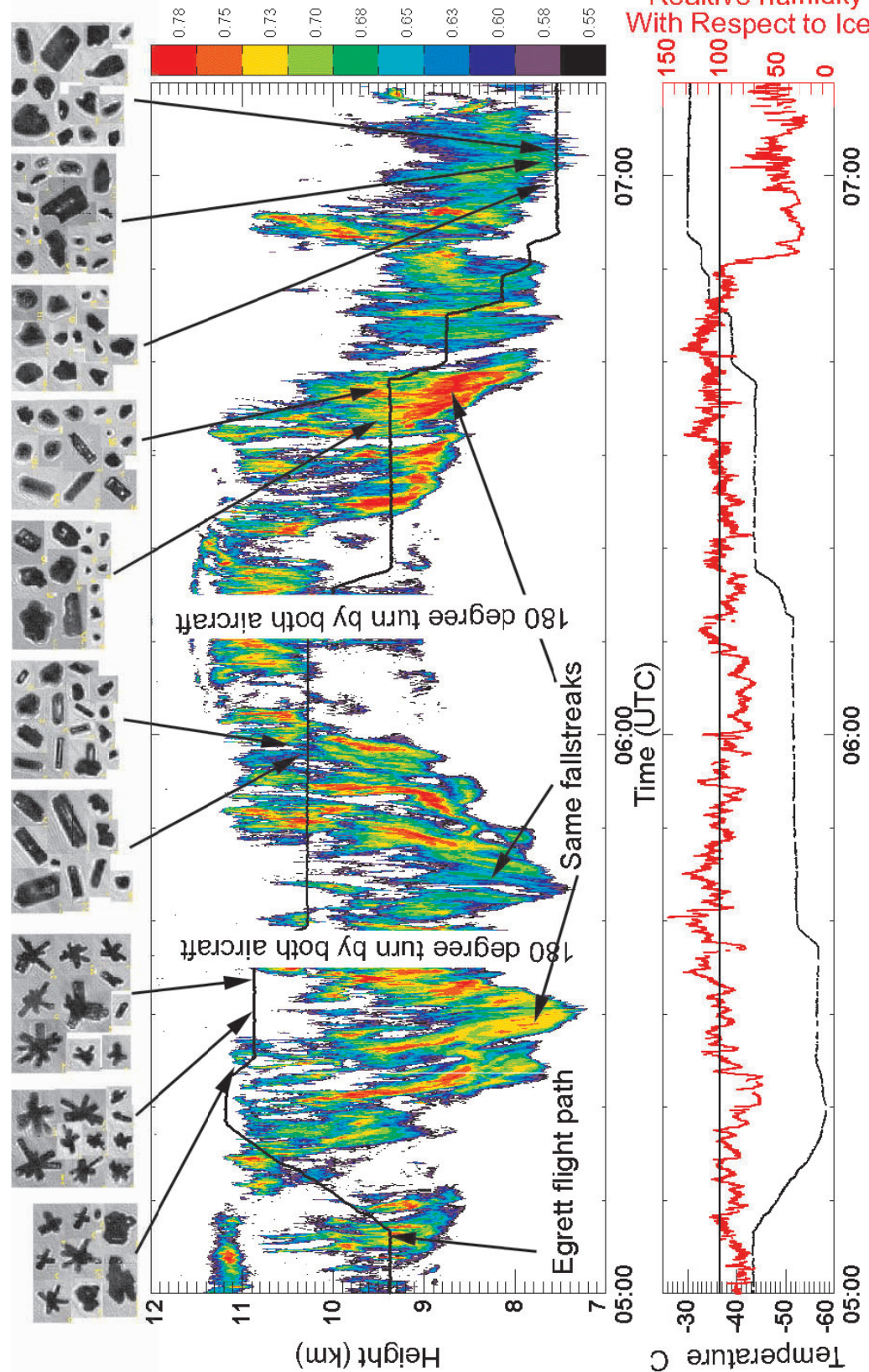

흐

을

펄

옹

छ

을

ब

का

은

吾承

밀

콘

ฐٓ

워

응

บ.

르의

क⿺⿻一⿰冫⿰亅⿱丿丶丶⿱⿰㇒一乂

تี

过

家晋

更

은

을

氙音寻

인

흔

60.07

츨

วิํㅇㅇ

ธี

象气

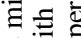

要

$\exists=$

․ㅡㄹ 을

.

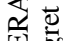

$\sum$ II

되 을

氜

空。

능

娄

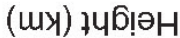

ว әпฺฺеגәduә।

을 
processing over 100 particles per video frame; this allows, in theory, particle data collection rates greater than 1000 particles per second to be attained. Individual particle images, with near black-and-white photographic quality, are produced and recorded allowing relatively easy habit classification either using manual or, more generally, automated computer image recognition algorithms. As the focus information, mean light intensity, arrival time as well as the $(x, y)$ position within the image plane are recorded for each detected particle, a variety of different techniques can be applied to correct for the local particle concentration due to coincidence (which is further a function of particle size) and the mis-sizing due to the particle being out of focus (i.e. its varying distance from the focal plane). These corrections are described and evaluated by Lawson and Cormack (1995), Korolev (1998) and Korolev et al. (1998).

Additional corrections, to take account of the variation of focus and depth of field as a function of 2D particle position within the CPI image plane, have also been investigated. These are important for improving the accuracy of sizing smaller particles, with particle diameter $D_{\mathrm{p}}<30 \mu \mathrm{m}$. These corrections, based on the approach of Korolev et al. (1999b), make use of the in situ measured image focus combined with laboratory calibrations of the instrument. Rather than using the spherical glass beads to determine these corrections, realistic ice crystal analogues of known dimensions and for various crystal habits were used. This novel approach is described by Ulanowski et al. (2004) and Connolly (personal communication, 2004). These corrections did not rely on fixing the sample volume of the CPI with, for example, that from a $2 \mathrm{D}-\mathrm{C}$ as has been used in recent studies. Figure 3 shows application of these corrections to the EMERALD-1 CPI spectra. Very good agreement between the FSSP and CPI numbersize distributions is achieved under most of the conditions encountered.

\section{(b) Microphysics instrumentation: use of the FSSP-100 in ice clouds}

Despite its often quoted sampling limitations, the FSSP has recently proved useful in ice-cloud measurements for determining total number concentrations, particularly where specific crystal habits and small sizes dominate (Ivanova et al. 2001; Lawson et al. 2001). This usefulness also appears to extend to sizing small ice crystals albeit approximately. Although the presence of significant numbers of very large ice crystals, particularly in mixed-phase clouds, can cause intractable problems for the particle counting and sizing performance of the instrument (Gardiner and Hallett 1985), the response appears to be significantly better in populations dominated by small spheroidal or irregular ice crystals where a semi-quantitative measure of the total concentration can be obtained (Baker and Lawson 2002). This is important, particularly in the light of the unexpectedly very high concentrations of small $(<30 \mu \mathrm{m})$ ice crystals recently observed (e.g. Lawson et al. 2002). We also have observed very high concentrations of ice particles in the cirrus clouds encountered during EMERALD-1, which were fully glaciated, as suggested by the CPI. Since temperatures in these clouds are generally below the homogeneous droplet nucleation temperature, the presence of supercooled water droplets is unlikely. These observations are consistent with and support the observations by Lawson et al. (2002).

There is, however, currently some debate as to whether these observations could be influenced by an as yet unquantified sampling artefact. The FSSP data recorded during EMERALD tend to support the observed high concentrations of small ice crystals in cirrus, although this does not rule out a similar sampling artefact in the FSSP instrument (Field et al. 2003). One such potential artefact that has been suggested is the break-up of large ice crystals on the inlet of the CPI and FSSP creating a 'shower' of smaller particles. This has been observed for droplets (Field et al. 2003) and was discussed by 


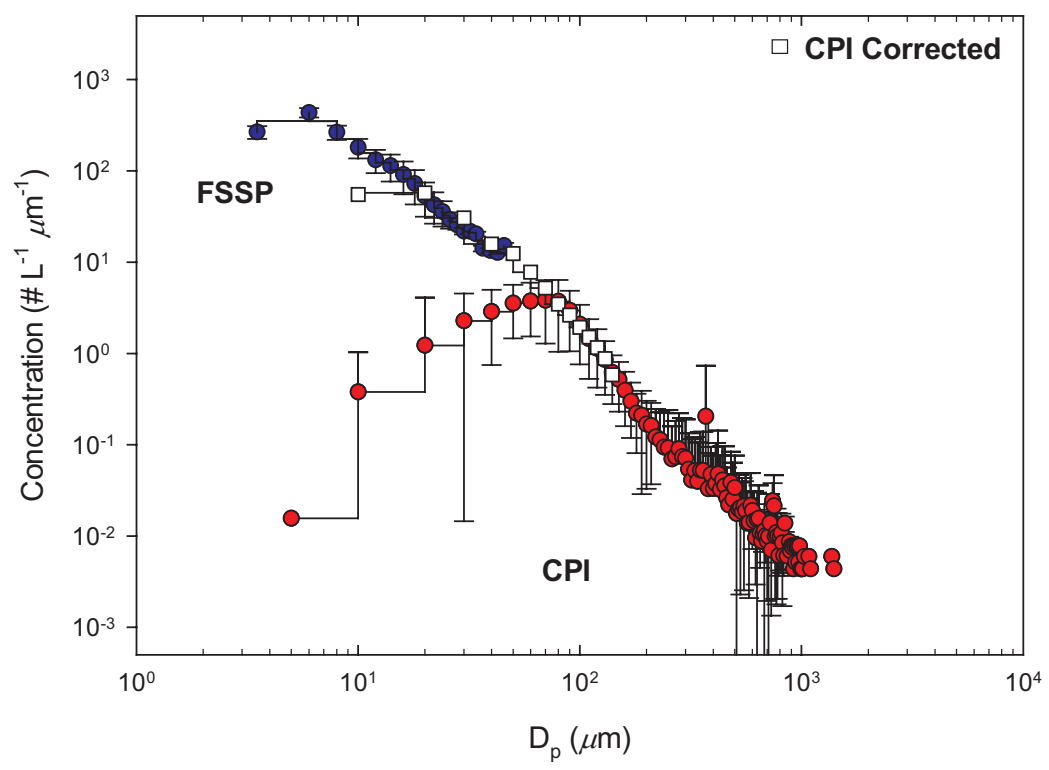

Figure 3. Combined particle-size distribution spectra from the cloud particle imager (CPI) and forward scattering spectrometer probe (FSSP) averaged over all EMERALD-1 flights (error bars are standard deviations). The open squares show the corrected spectra for small crystal sizes according to Connolly (personal communication, 2004).

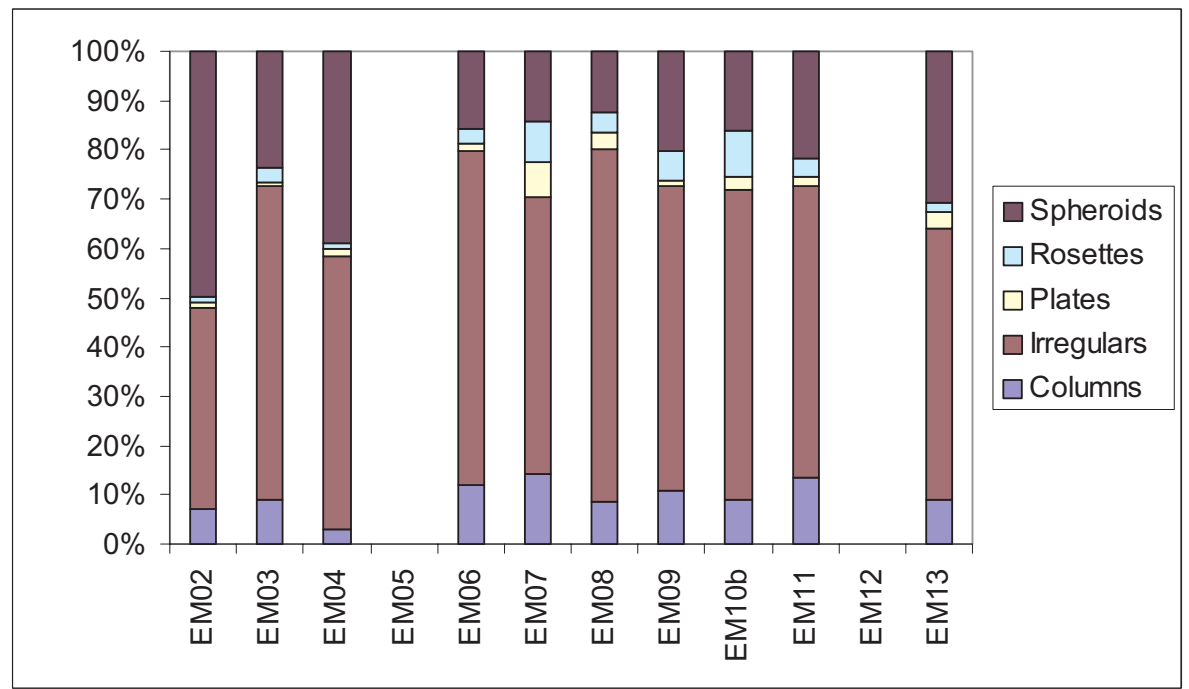

Figure 4. Summary of cirrus ice crystal habit contributions for all EMERALD-1 flights except EM5 and EM12 (see Table 1).

Lawson et al. (2001). We are of the opinion that this effect does not influence most, if any, of the results presented here for several reasons.

First, ice crystals with a large diameter $\left(D_{\mathrm{p}}>100 \mu \mathrm{m}\right)$, which would have a potentially greater propensity for contributing to this effect (private communication, 
John Hallet 2002) are present in very low concentrations, and a time sequence frameby-frame analysis of the captured images does not show evidence of association of large crystal formations (e.g. rosettes) with high concentrations of smaller particles that may be fragments (e.g. bullet rosettes with individual bullets) to any great degree. Analysis of particle images on an inter-arrival-time basis showed little evidence of this breakup contributing to the observed concentrations, at least under conditions pertaining to the cirrus clouds observed. It is possible that when large particle concentrations are present this effect may occur, e.g. during flight EM02. Secondly, there is no evidence of multiple crystal images recorded per $20 \mathrm{~Hz}$ frame, as might be expected due to showers of particles being produced by large-particle break-up. For the time being the data obtained in EMERALD-1 suggest this effect does not contribute significantly to the observations in this experiment, and thus will not alter the overall conclusions presented here. Further similar evidence has been forthcoming from a more recent experiment, where larger more complex chain-like crystal structures also appear to survive sampling by the instrument.

\section{EMERALD CIRRUS DATABASE MEAN PROPERTIES}

Twelve EMERALD flights were designed to measure in situ cirrus microphysics, turbulence and long-wave infrared radiation, in tandem with an airborne lidar flown on the King Air (Cook et al. 2003; Whiteway et al. 2003). CPI and FSSP-100 data were collected on all flights, ten of which encountered well-developed cirrus and which form the basis of the analyses presented here. Table 1 summarizes the mean cirrus cloud characteristics based on data from all the flights. The cloud base and cloud top were determined using the airborne lidar and in most cases these showed significant variation, e.g. flight EM09 in Fig. 2 shows the cloud top varying from 9 to $12 \mathrm{~km}$. These large vertical variations exhibited across the horizontal extent of the cloud would have led to difficulties in interpretation of the in situ microphysical measurements without the aid of the airborne lidar to guide the microphysical investigations.

Ice particles were recorded at cloud temperatures ranging from -15 to $-64{ }^{\circ} \mathrm{C}$, but the majority of cases were colder than $-41^{\circ} \mathrm{C}$. This implies e.g. that the planar growth regime $\left(-22\right.$ to $-40{ }^{\circ} \mathrm{C}$ ) should have been encountered post nucleation. Recent ice nucleation and ice crystal growth experiments conducted in the AIDA* large expansion chamber (Connolly et al. 2004), showed that no plates were produced under conditions with a simulated low-velocity updraught. Average ice crystal concentrations were found to range from 136 to $1266 \mathrm{~L}^{-1}$, however, within individual clouds maximum concentrations could be as high as $7000 \mathrm{~L}^{-1}$, recorded on a 1-minute integrated basis, and very occasionally reached in excess of $20-30000 \mathrm{~L}^{-1}$ at specific locations and on very small spatial-scales. Again, these very large concentrations must be assessed in terms of the known limitations of the instruments. Despite this, these high ice crystal concentrations were 'confirmed' to within a factor of two, within the limitations discussed above, by the total electronic event strobes recorded by the FSSP-100.

Throughout the remainder of this paper total concentrations reported will be those measured by the CPI, with the understanding that the concentrations are replicated by those measured by the FSSP, but on average underestimated by a factor of two.

Average maximum cirrus cloud ice crystal dimensions (based on the length of the longest crystal axis) as recorded by the CPI, $\bar{D}_{\text {pmax }}$, were typically only $70 \mu \mathrm{m}$. If the ice

* Aerosol Interactions and Dynamics in the Atmosphere-a European experimental aerosol dynamics chamber facility in Karlsruhe, Germany. 


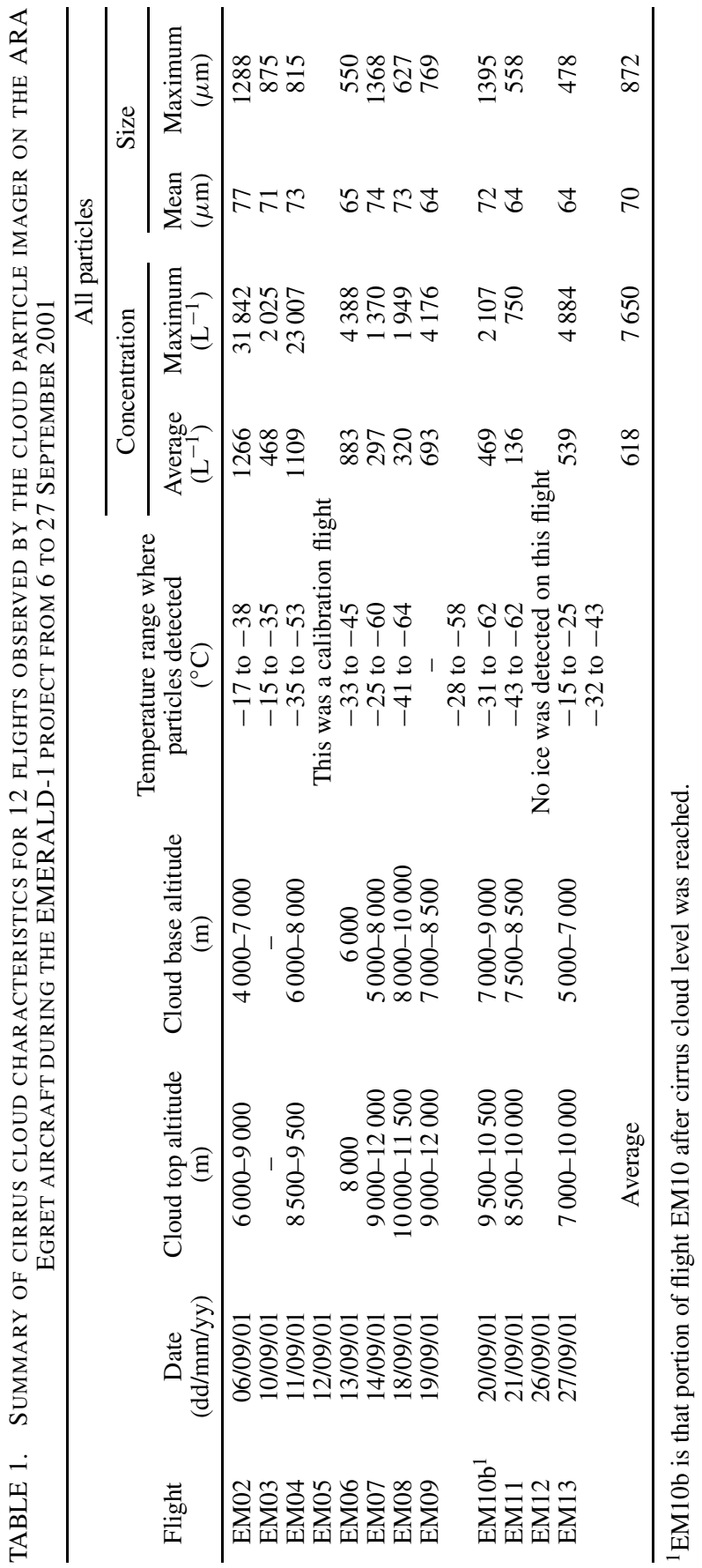


crystal data were averaged over all flights it was found that they presented a remarkably narrow, uniform distribution, peaking between only 64 to $77 \mu \mathrm{m}$. However, within each cloud significant variation could occur at specific locations. The average maximum crystal dimension detected within a $60 \mathrm{~s}$ cloud period for example was $872 \mu \mathrm{m}$, and the observed population ranged between 478 to $1395 \mu \mathrm{m}$. These large ice crystals were generally quite rare and confined to specific locations, or were associated with specific dynamic conditions. The clarity of images provided by the CPI and the automated image recording and analysis firmware and software, allows improved accuracy of estimation of ice crystal habit and crystal cross-sectional area. The contribution to the average total concentration of ice crystals for each flight according to individual habit classes is shown in Fig. 4.

\section{(a) Summary of ice crystal habit, concentration and size}

(i) Habit variation. The overwhelming majority of ice crystals encountered during all flights were classified as small irregular particles, comprising typically two thirds of the total concentrations measured, with up to a quarter being classed as 'spheroidal'. Note that the latter classification is not to be confused with spheres i.e. droplets which are relatively straightforward to identify using CPI. The use of the term spheroidal is probably debatable, as a significant fraction of these were very small and difficult to resolve below $20 \mu \mathrm{m}$ in size, and could possibly be irregular or aggregates or possibly proto-bullet rosettes whose growth was recently initiated. It has been suggested as unlikely that these very small ice crystals are aggregates, based on recent laboratory studies and because the collection efficiencies for such small plates is very small, but this cannot be ruled out as the instrumentation to observe these clearly is not available. The remaining observed habits were overwhelmingly dominated by bullet rosettes and columns, whilst side plates and 'pristine' plates were very rarely observed. In certain regions the transition from bullet rosettes to rosettes with side plates was observed. This is consistent with conclusions based on the majority of airborne and laboratory observations to date (Bailey and Hallet 2002).

Figures 5(a)-(e) show a breakdown of the ice crystal data averaged over all flights. Figure 5(a) is the concentration frequency histogram summed over all flights, and shows median concentrations of $640 \mathrm{~L}^{-1}$ and approximates a normal distribution. There is, it could be argued, a small bias towards smaller concentrations, possibly caused by the inclusion of particles not completely resolved by the CPI because of the minimum sizing and sample volume issues. The occurrence of high concentrations is infrequent but significant.

If we next consider the relative contributions as a function of the different ice crystal habits, Figs. 5(b)-(e), then we see that small 'irregular' and spheroidal classified crystals (with aspect ratios close to one) dominate the spatially averaged picture observed in these cirrus clouds. The next most common crystal type observed is the bullet rosette, examples of which are shown in Fig. 6. These were typically pristine six-branch rosettes, which is the typical crystal habit initially growing from frozen water droplets at temperatures below about $-41^{\circ} \mathrm{C}$ (Bailey and Hallet 2002). The frequency of observed concentrations for bullet-rosettes (Fig. 5(d)) shows that on average this crystal type contributed to typically only $6 \%$ of the total concentration observed. However, due to their significantly larger average dimensions they will contribute significantly to the total ice surface area within these clouds. Furthermore, the transition from identifiable proto or 'germ' bullet rosette to large more open rosettes is difficult to gauge. Flight EM02 was notable in that nucleation and growth to form bullet rosettes was followed 

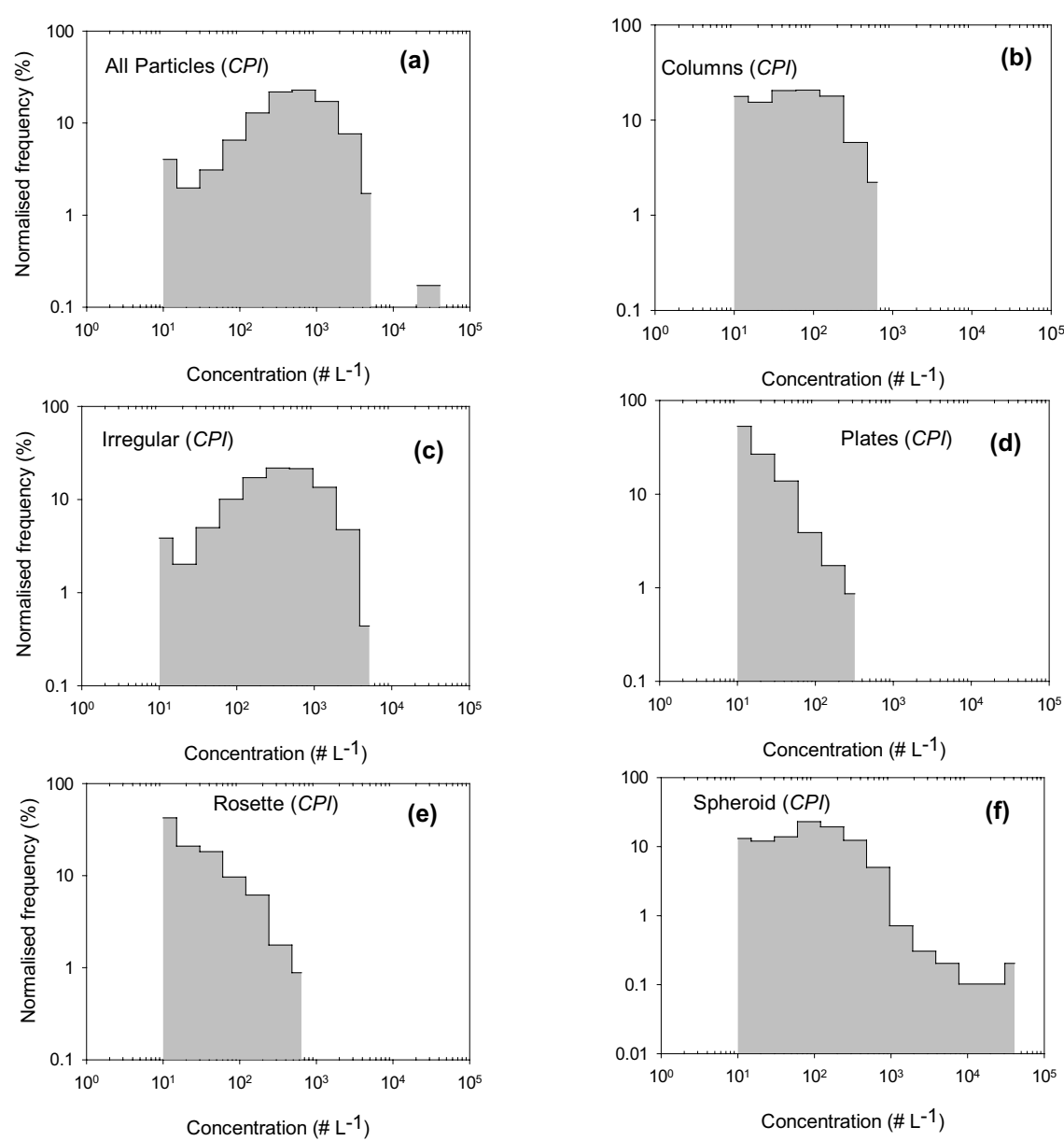

Figure 5. Frequency histograms of the concentrations of ice particles as a percentage of all in-cloud events for all EMERALD-1 flights: (a) all ice particles having cloud particle imager (CPI) measured diameters $>10 \mu \mathrm{m}$; (b) to (e) as (a) but for single crystal habits shown.

by transition to the plate-growth regime where significant side-plate or S3 type (using the classification devised by Magono and Lee (1966)) crystal formation could occur, as shown in Fig. 7(a). This could result in large and very complex crystal shapes. It should be noted that the automated habit-detection software classified these under the general 'rosette' heading.

Pristine plates showed a similar distribution but were extremely rare. One example is shown in Fig. 7(b), from EM02, but as cautioned by Bailey and Hallett (2002), one should be careful not to emphasise the presence of such aesthetically pleasing habits without commensurate statistical data and, in fact, this may have become detached from a P3 with side-plate combination.

Finally, the last two identifiable crystal habits examined, spheroidal and columns (Fig. 7(c)), showed general similarities, with a relatively uniform number of occurrences for all concentrations, which were on average much lower. Table 2 is a summary of the mean observed concentrations averaged over all flights, and the percentage contribution 
by each crystal habit to the average. Here the so-called irregular particles dominate (Fig. 7(d)) comprising almost two thirds of all particles measured.

(ii) Ice crystal-size distribution. The ice crystal-size distribution based on all particle types detected by the CPI is shown in Fig. 8(a) for each individual flight. The spectra are relatively similar from flight to flight with the exception of EM02 (which was the flight on 6 September 2001). There is only a relatively small change in modal maximum crystal dimension between flights. The characteristic roll-off in CPI response, discussed previously, is noticeable below approximately $50 \mu \mathrm{m}$ but is not always observed, e.g. EM02 shows no detectable roll-off in concentration. Flight EM02 is interesting in that a second mode at approximately $200 \mu \mathrm{m}$ is seen with much higher concentrations of larger ice crystals than other flights. EM02 also displayed the highest average and highest maximum ice crystal concentrations of any of the cirrus encounters, as well as the largest mean crystal size. This particular cloud was among the lowest observed, although the vertical extent changed significantly during the measurement period, with cloud base varying from 4 to $7 \mathrm{~km}$, and cloud top from 6 to $9 \mathrm{~km}$. As might be expected, this led to the largest mean crystal size overall but the ice-size spectral characteristics were very different compared to the other flights.

The mean dimension of all crystals detected, using a 1-minute in-cloud integration period, was generally confined to a very narrow range between 60 and $100 \mu \mathrm{m}$, with twice as many ice particles observed in the 80 to $100 \mu \mathrm{m}$ band compared with those in the 60 to $80 \mu \mathrm{m}$ band. With the proviso that the data presented so far are ensemble averages, and that the CPI exhibits a decreasing response in this size range, these crystal sizes would appear to be generally representative of cirrus clouds. Figure 8(b) shows the average FSSP spectra observed during each flight, and these modal behaviours are consistent with the CPI spectra in most cases. If presented with such 'average' data, one might conclude that these clouds are well mixed on time-scales that are comparable with growth times associated with the mean crystal dimensions observed. It might be argued, however, that the measurements presented were biased in some way towards specific parts of the clouds, and that the average picture subsequently presented is perhaps unrepresentative or that the data samples were restricted to early growth stages of cirrus. However, with the advantage of the simultaneous Lidar scans we know that the data were collected from a large number of different cloud regions as a function of cloud depth in each cloud case-study, with repeated cloud penetrations of the same cloud covering time-scales whose duration is similar to expected cirrus cloud evolution timescales. Furthermore, significant dynamical events were observed to contribute to large variations in cloud structure within individual case-studies. We are confident therefore that these ensemble-averaged data are truly representative of mean cirrus conditions under the prevailing meteorological conditions at this location.

The frequency distribution of observed crystal dimensions for individual habits present a very different picture. The mean lengths for solid columns, for example, show a similar pattern to that for all particles irrespective of habit, but the difference between the numbers of occurrences, e.g. between 60 and $100 \mu \mathrm{m}$ and other sizes, is not as distinct as for the irregular or the total particle distributions. The distribution of plates, although rarely observed, shows that most of these had mean dimensions between 150 and $250 \mu \mathrm{m}$ with very few occurrences outside these sizes. Spheroids were detected whose sizes were between 40 and $80 \mu \mathrm{m}$ on average. What is interesting is that the distributions of the less frequent habits show sizes confined to relatively narrow size bands that account for up to $68 \%$ of their total concentrations. This might suggest that the conditions in which they were initiated and subsequently evolved are not typical 

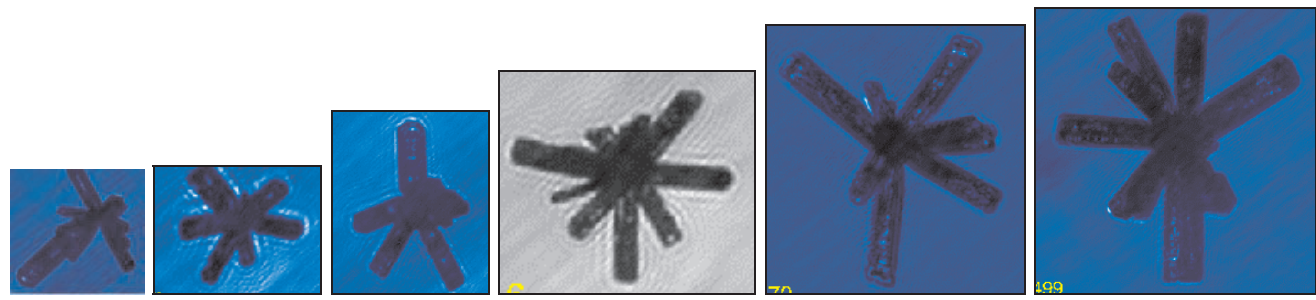

Figure 6. Examples of bullet-rosettes encountered on some EMERALD-1 flights, with maximum dimensions of 40 (flight EM07), 49, 65 (EM06), 216, 370 (EM04) and 499 (EM06) $\mu \mathrm{m}$.

(a)
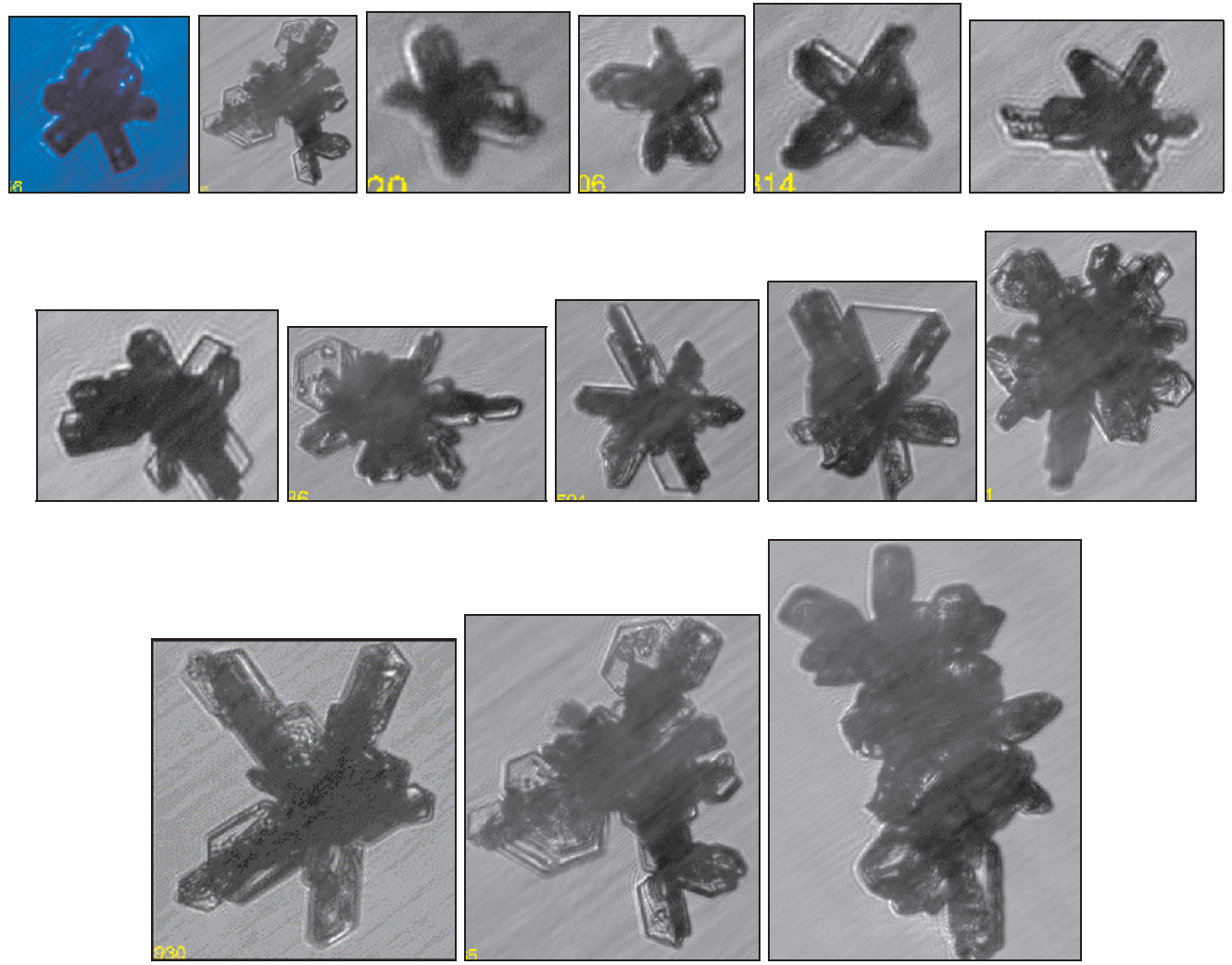

Figure 7. Examples of ice forms from EMERALD-1 flights. (a) Bullet rosettes undergoing transition to plate growth (Magono and Lee (1966) classification S3 with side-plate combination) from flights EM02 and EM04. Maximum dimensions are 56, 85, 220, 306, 314, 349, 358, 496, 504, 643, 741, 930, 985 and $1153 \mu \mathrm{m}$, respectively. (b) A rarely observed type (Magono and Lee classification $\mathrm{C} 1 \mathrm{~h}$ ) comprising skeletal thick plates and hexagonal plates from flights EM02 and EM03, sizes are 82, 57 and $21 \mu \mathrm{m}$. (c) Columns with lengths 55, 91, 144, 186, 223 and $482 \mu \mathrm{m}$ from flights EM02, EM04, EM06, EM08, EM04, EM04 and EM10, respectively. (d) Examples from a time series of the many small irregular germ bullet rosettes or plate assemblages encountered during all flights, sizes range from $30-80 \mu \mathrm{m}$. 
(b)
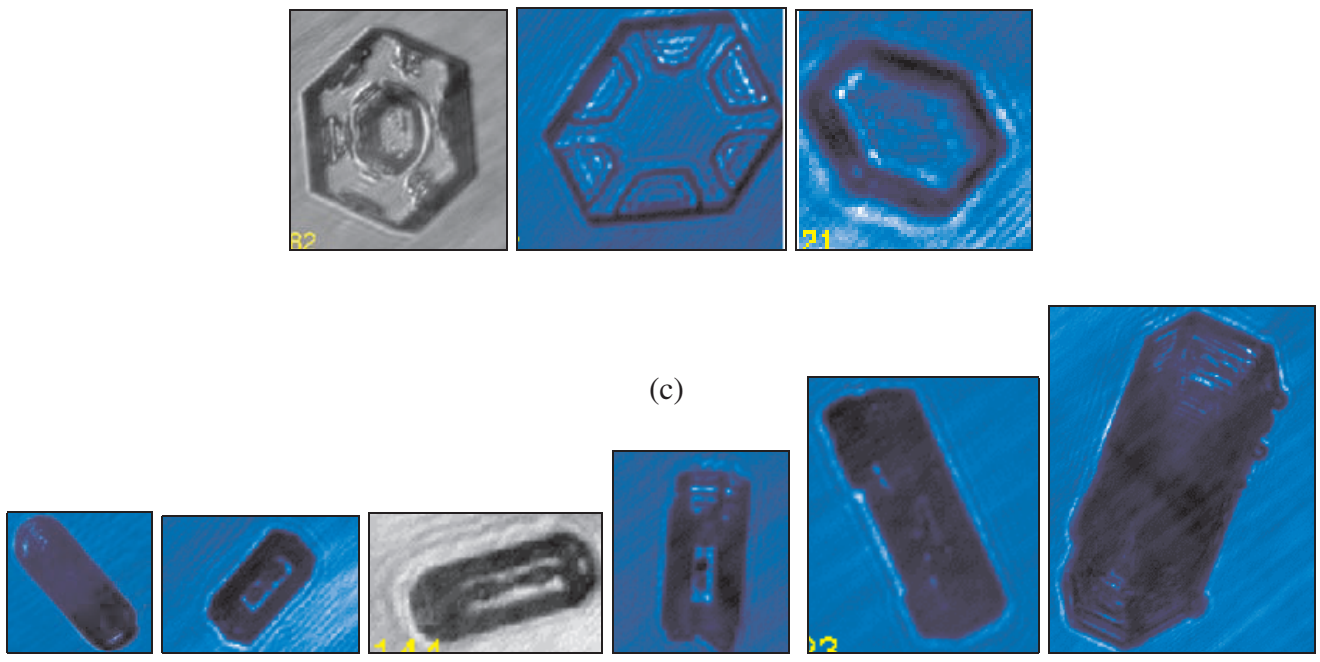

(d)
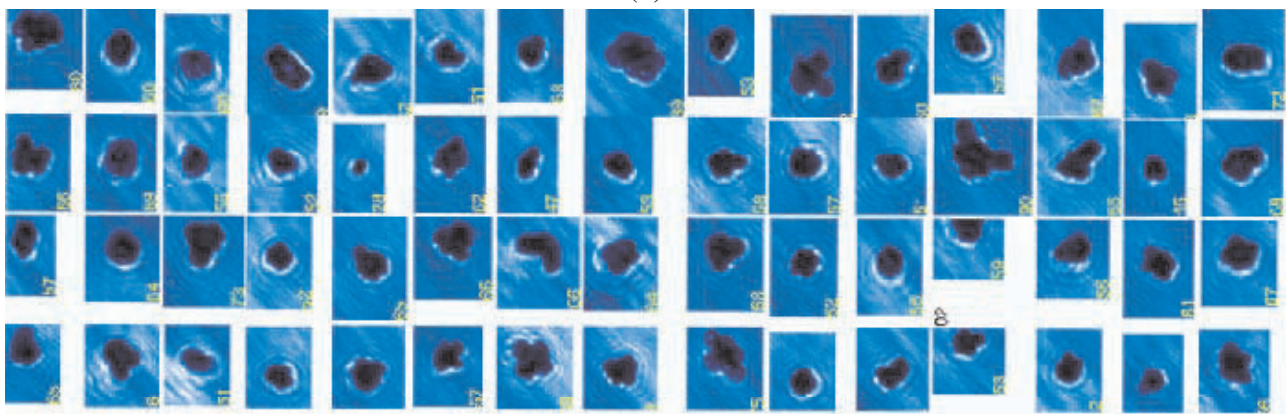

Figure 7. Continued.

TABLE 2. STATISTICS OF CRYSTALS IN EACH HABIT CLASSIFICATION CATEGORY WITH RESPECT TO THE TOTAL MEASURED

\begin{tabular}{lcccrr}
\hline & Irregular & Spheroidal & Column & Rosette & Plate \\
\hline Mean concentration per habit $\left(\mathrm{L}^{-1}\right)$ & 396.0 & 199.9 & 59.3 & 23.2 & 13.8 \\
Percentage of total & 59.5 & 24.1 & 9.7 & 4.2 & 2.5 \\
Standard Deviation & 9.8 & 12.1 & 4.0 & 3.3 & 2.2 \\
\hline
\end{tabular}

of the conditions encountered during the cloud penetrations. The bullet rosette size distribution, on the other hand, exhibited an approximately normal distribution, with maximum crystal dimensions between 150 and $200 \mu \mathrm{m}$ indicating that there are regions within these cirrus clouds that provide sufficient dynamic time-scales for growth to these sizes, and that this particular observation can be used to indicate maximum-growth timescales within these clouds. 


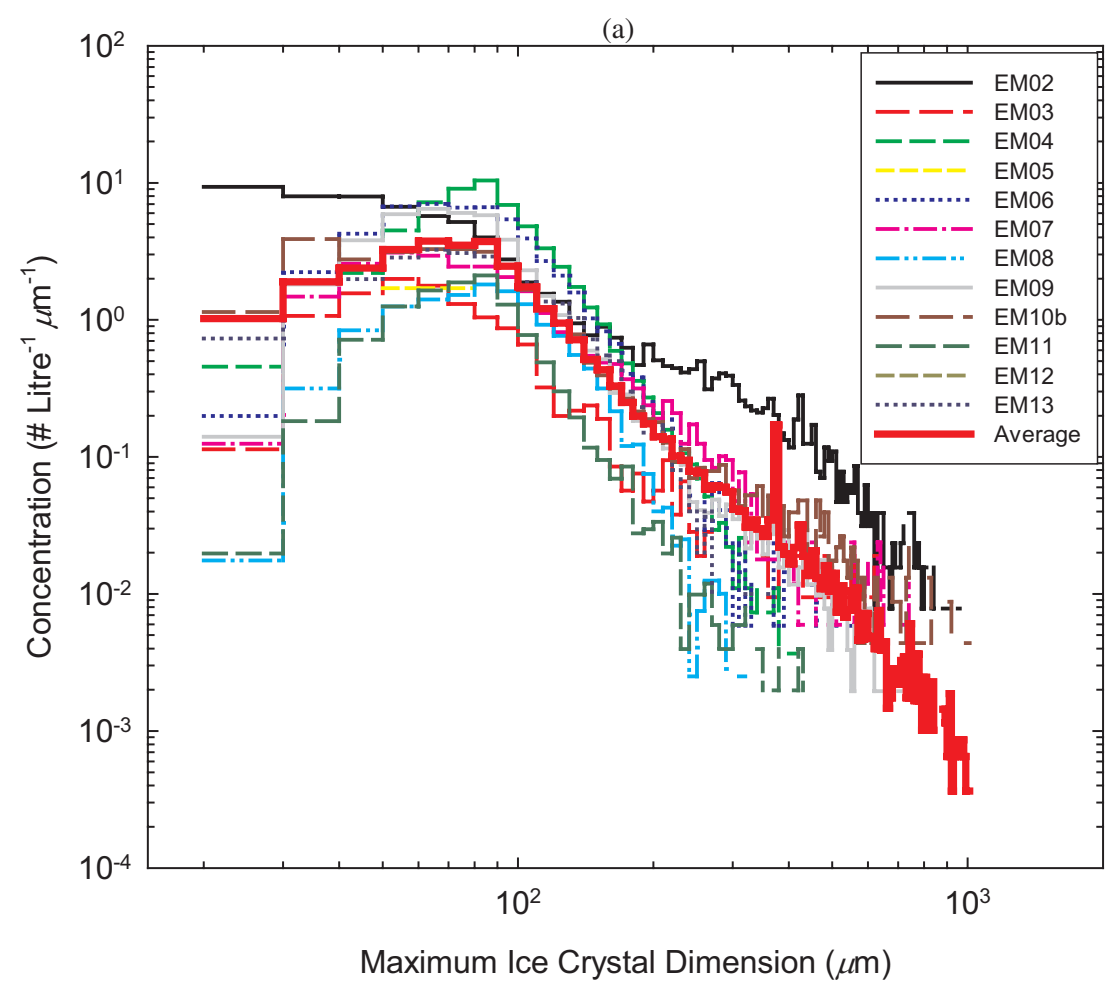

(b)

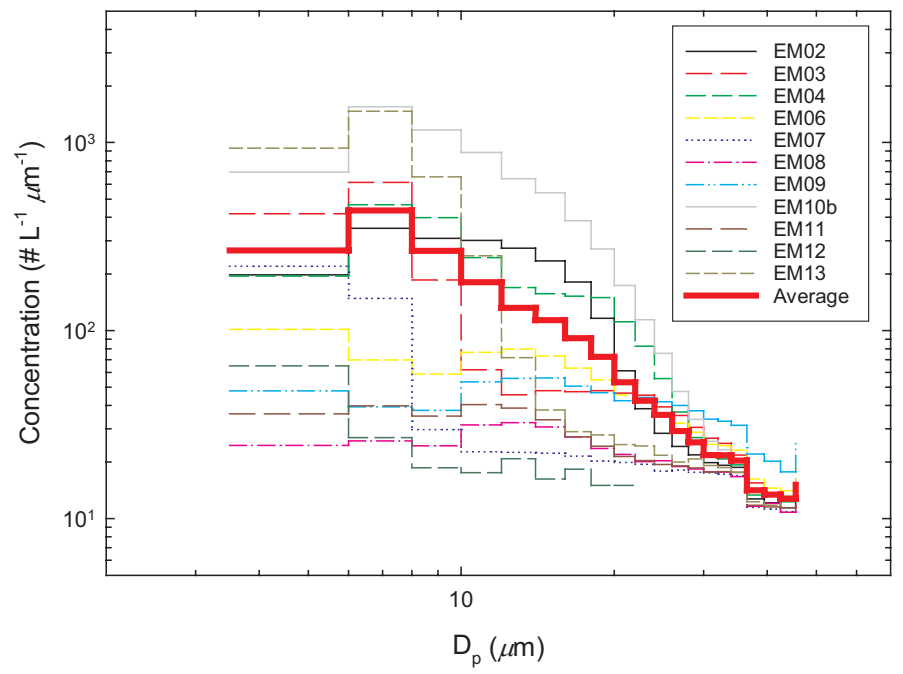

Figure 8. For each of the EMERALD-1 cirrus flights that encountered ice particles: (a) cloud particle imager (CPI) ice crystal concentration-size distributions (uncorrected) for all crystals; (b) forward scattering spectrometer probe (FSSP) number-size distributions. In both cases the red bold line is the mean of all flights. Size is given by $D_{\mathrm{p}}$, the particle diameter. 
(a)

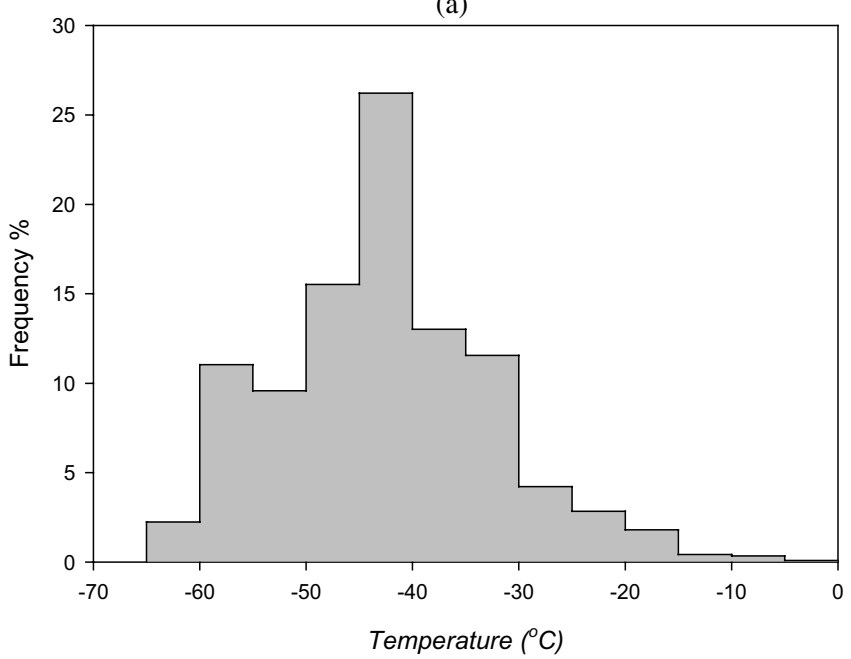

(b)

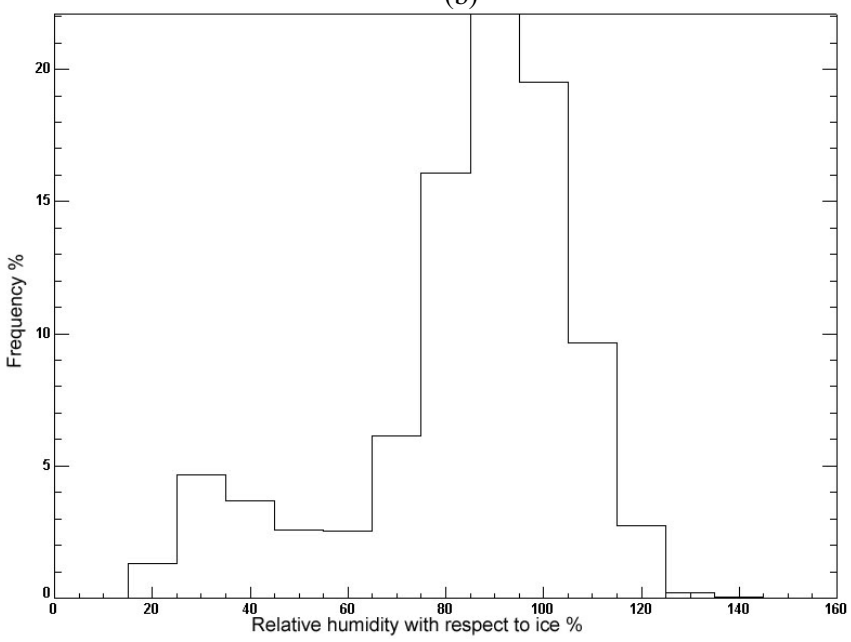

Figure 9. Frequency distributions of: (a) temperature for all in-cloud periods (including one low-level water cloud encountered during flight EM02); (b) cirrus in-cloud relative humidity with respect to ice for all EMERALD-1 flights.

\section{RELATIVE HUMIDITY WITH RESPECT TO ICE IN CIRRUS CLOUDS}

Growth rates of ice crystals are critically dependent on $R H_{\text {ice }}$, and here we present a brief statistical summary of in-cloud $R H_{\text {ice }}$ observations during EMERALD. These were used for ice crystal growth studies described below. The $R H_{\text {ice }}$ measurements from all twelve flights were processed for in-cloud measurements only, again using an integration time of one minute. The criteria used to define an in-cloud event were determined by whether the CPI and/or the FSSP-100 detected a particle event, i.e. $N_{\mathrm{CPI}}$ and/or $N_{\text {FSSP }}>0$. This sorting criteria resulted in 1144 minutes of in-cloud data for analysis. The resulting frequency histogram of $R H_{\text {ice }}$ is shown in Fig. 9(b). 


\section{(a) In-cloud criteria and analysis}

In-cloud regions exhibited a mean $R H_{\text {ice }}$ of $87.2 \%$ with a standard deviation of $\pm 18.5 \%$. This highlights the difficulty in defining an in-cloud region, as one might expect the mean to be at ice supersaturation for these 'clouds'. $R H_{\text {ice }}$ varied from a minimum of $23.7 \%$ to a maximum of $186.7 \%$. Regions of low $R H_{\text {ice }}$, are most likely related to those regions where fall streaks were observed as discussed later. A comparison between this dataset and the measurements conducted during the INCA project, which is described by Ström (2002), shows significant differences. The INCA database measured cirrus clouds from both the northern and southern hemispheres, and showed a maximum frequency of occurrence for $R H_{\text {ice }}$ close to $100 \%$. In the southern hemisphere $51 \%$ of the INCA in-cloud $R H_{\text {ice }}$ data were found to be in regions where the relative humidity was generally above $105 \%$ (as compared to $31 \%$ for the northern hemisphere). For the EMERALD southern hemisphere dataset only $21 \%$ of the incloud data were found to be in regions where $R H_{\text {ice }}$ exceeded $105 \%$. This difference is partly due to the averaging of our data over 1-minute intervals, which did not include a requirement for continuous 'cloud events'. However the nature of the cloud sampling methodology used in EMERALD, with directed cloud penetrations, meant that a very high proportion of the dataset could be classed as continuous cloud as supported by the high-frequency FSSP and CPI data. A more detailed analysis of higher-frequency datasets will be reported in further papers. There are additional differences in the definition of in-cloud criteria. The criteria used for the INCA dataset was based on information recorded by a Polar nephelometer instrument (Gayet et al. 2002), which was required to show an extinction threshold greater than $0.05 \mathrm{~km}^{-1}$ for 4 consecutive seconds in order for $R H_{\text {ice }}$ measurements to be classed as in-cloud. The sample volume limitation of the nephelometer, meant that this criterion could lead to missing data from low-concentration or sub-visible cirrus, as discussed by Ström (2002). It should also be emphasized that the EMERALD dataset is for clouds within a rather narrow midlatitude region of the southern hemisphere.

Most of the clouds studied showed limited regions of saturation with respect to liquid water. These regions occupied only a very small fraction of the cloud passes, however, they are sufficient to indicate that the homogeneous freezing of aerosol followed by freezing of supercooled water droplets is a significant source of ice crystals in these clouds.

\section{(b) In-cloud temperature}

The same analysis when applied to in-cloud temperature (Fig. 9(a)) showed that approximately $65 \%$ of all 'cloud' events measured occurred below $-40{ }^{\circ} \mathrm{C}$ (with $39 \%$ less than $-45^{\circ} \mathrm{C}$ ) where homogeneous nucleation dominates ice formation from any supercooled water. The proportion in the 'heterogeneous' ice-nucleation region $(0>T>$ $-35^{\circ} \mathrm{C}$ ) was $35 \%$. The mean in-cloud recorded temperature averaged over all flights and all cirrus levels was $-42.8^{\circ} \mathrm{C}$ with standard deviation $\pm 10.2 \mathrm{degC}$. The minimum temperature recorded was $-63.6^{\circ} \mathrm{C}$.

\section{NUCLEATION FREEZING PROCESSES}

Very few measurements of ice-forming nuclei at cirrus levels in the atmosphere are available, and it is probable that the somewhat static picture of nucleation regimes is highly variable depending on the amount of surface material that has been transported to this region of the atmosphere. Heymsfield (1972) suggests this might be of the order 
$10^{3} \mathrm{~L}^{-1}$. In some EMERALD-1 cirrus cases ice-forming regions were detected where conditions were supersaturated with respect to ice but under-saturated with respect to water. In these conditions it is to be expected that ice crystals will be formed by deposition or immersion nucleation and not by homogeneous freezing. However, there are still uncertainties surrounding the exact nature of the process that may allow homogeneous freezing under very low-saturation conditions. Table 1 shows that average concentrations of crystals in the clouds were in the range $10^{2}$ to $10^{3} \mathrm{~L}^{-1}$, with peak concentrations in the range $10^{3}$ to $10^{4} \mathrm{~L}^{-1}$. Hence, ice crystal concentrations were within an order of magnitude of the expected number of ice nuclei at cirrus levels in these cases.

Although the homogeneous-nucleation argument is favoured at the observed temperature regimes, there are some observations from regions that are unsaturated with respect to water (e.g. during flights EM02 and EM04 near cloud base), and hence the likely process dominating is deposition nucleation leading to pristine ice particles. It should be noted also that during flights EM02 and EM04 larger fractions of spheroidal ice particles were detected than in any other flights. The lowest temperatures at cloud top were observed during EM07, EM9 and EM10b, and during these flights it was found that the greatest fractional contribution to total ice concentrations was due to bullet rosettes.

\section{ICE CRYSTAL AREA ANALYSIS}

The cross-sectional area of ice crystals as a function of their habit is an important parameter for the representation of cirrus clouds in general circulation models. It is only recently that direct measurements of the evolution of in situ cross-sectional areas of mixed-habit ice crystal ensembles in cirrus clouds have been performed (Heymsfield and Miloshevich 2003). We have examined an area-ratio parameter for several case-studies in the EMERALD data for consistency with current parametrizations for different ice crystal habits. The standard shape-sensitive area-ratio parameter $A_{\mathrm{r}}(D)=A /\left(\pi D^{2} / 4\right)$ was calculated, where $A$ is the cross-sectional area of the ice particle and $\pi D^{2} / 4$ is the area of the circle that bounds the maximum dimension, $D$, of the ice crystal. For planar particles $D$ is the maximum basal face dimension, for columns it is the length of the longest side, whilst for more complex shapes $D$ refers to the maximum dimension of the particle image projected onto a $2 \mathrm{D}$ plane. For a detailed review of the sensitivity of particle shape and diameter on $A_{\mathrm{r}}$ the reader is referred to the thorough discussions by Mitchell (1996) and Heymsfield and Miloshevich (2003). The general observation, as one might expect, is that $A_{\mathrm{r}}$ systematically decreases with increasing $D_{\mathrm{p}}$ for all habits that are relevant to cirrus clouds, and this is also true of the observations from EMERALD. Figure 10(a) shows the calculated $A_{\mathrm{r}}$ for columns observed during flight EM02, and is based on 2012 images. The overwhelming majority of columns are less than $200 \mu \mathrm{m}$ in size, with $A_{\mathrm{r}}$ tending to a value of 0.34 for the larger crystals. The behaviour of $A_{\mathrm{r}}$ is described well in this case by a five-parameter exponential decay function:

$$
A_{\mathrm{r}}(\text { Columns })=0.3389+0.3567 \exp \left(-0.0640 D_{\mathrm{p}}\right)+0.2027 \exp \left(-0.006645 D_{\mathrm{p}}\right) .
$$

The observations for rosettes (Fig. 10(b)) shows examples from EM02 and EM09 that are more scattered. Although the whole dataset is well constrained by the function:

$$
A_{\mathrm{r}}(\text { Rosettes })=-0.0604+0.876 \exp \left(-0.0252 D_{\mathrm{p}}\right)+0.506 \exp \left(-0.000268 D_{\mathrm{p}}\right) \text {. }
$$

There appear to be two different clusters within the dataset, possibly the result of two different growth-scale regimes associated with an additional stronger dynamic mode 
(a)

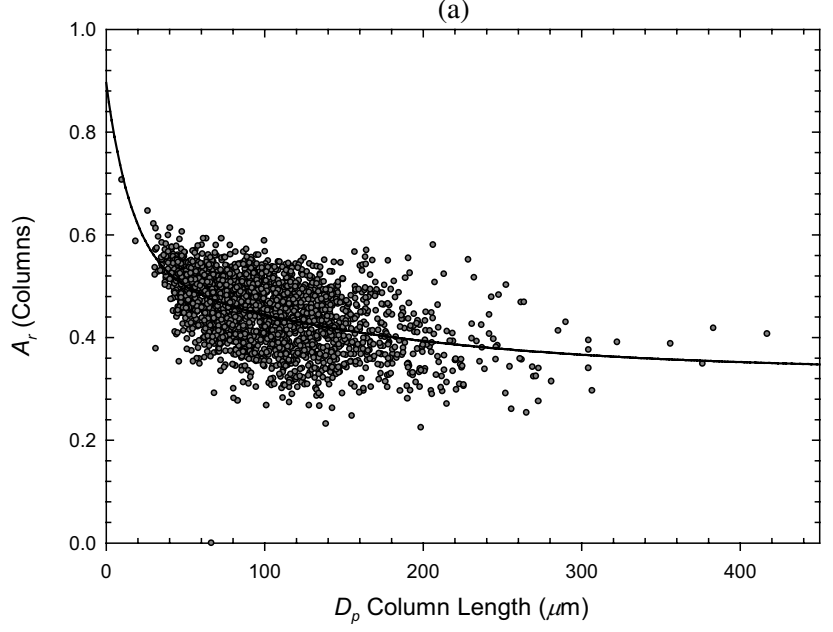

(b)

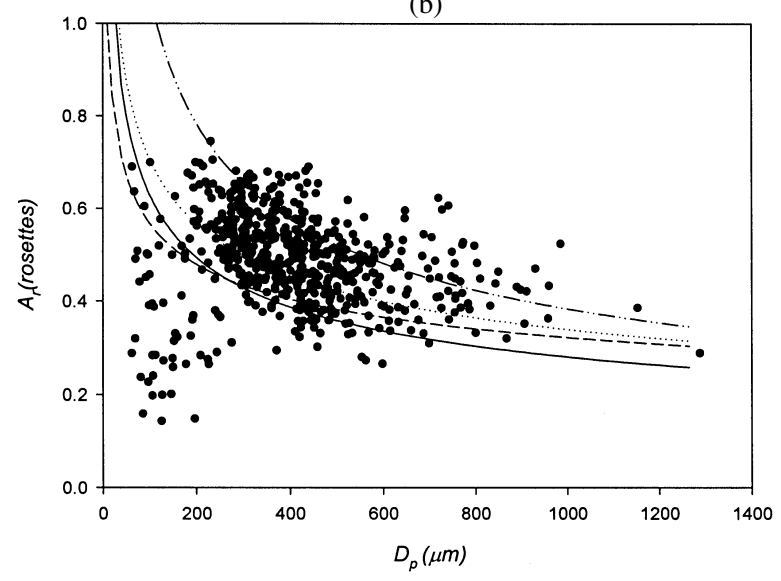

(c)

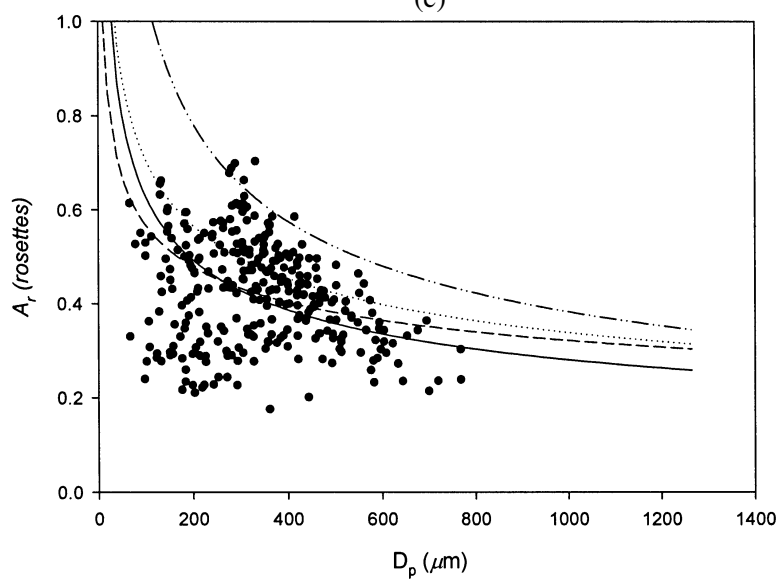

Figure 10. Area ratios, $A_{\mathrm{r}}$, in EMERALD-1 flights for: (a) columnar crystals observed during flight EM02; (b) rosettes observed during EM02 and (c) rosettes observed during EM09. All lines are parametrizations for rosettes from Heymsfield and Miloshevich (2003): single + aggregated given by full lines; aggregated given by dashed lines; single given by dotted lines; the double-dotted and dashed line is from Kajakawa and Heymsfield (1989) derived from laboratory studies. (d) Summary of $A_{\mathrm{r}}$ (columns) parametrizations for each flight and the combined dataset (EMcombined). 


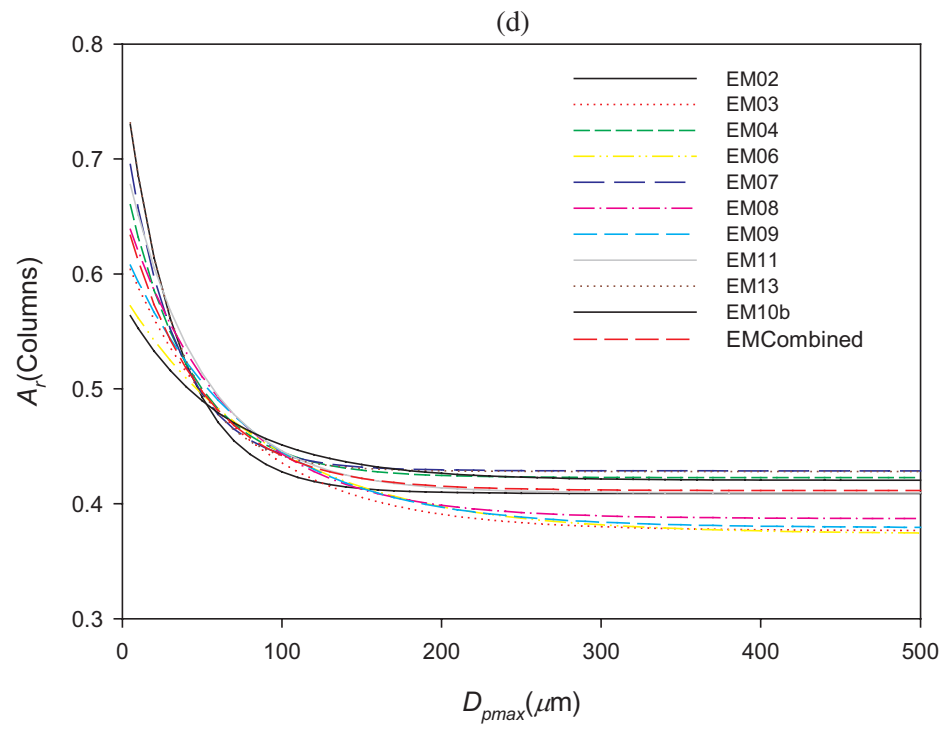

Figure 10. Continued.

in EM09. For the combined dataset the $A_{\mathrm{r}}$ parametrization for columns and rosettes becomes:

$$
A_{\mathrm{r}}(\text { Columns })=0.3356+0.3590 \exp \left(-0.0607 D_{\mathrm{p}}\right)+0.2013 \exp \left(-0.006247 D_{\mathrm{p}}\right),
$$

and

$$
A_{\mathrm{r}}(\text { Rosettes })=0.2295+0.9666 \exp \left(-0.0275 D_{\mathrm{p}}\right)+0.6870 \exp -\left(0.00024712 D_{\mathrm{p}}\right) .
$$

However, the regression coefficient, $R$, is only 0.54 . There are insufficient data to accurately parametrize plates although further analysis on new flights is continuing. If we use a simple, more applicable, two-parameter description of $A_{\mathrm{r}}$ as described by Heymsfield and Miloshevich (2003), then the relationship reduces to:

$$
A_{\mathrm{r}}=0.5314 D_{\mathrm{p}}^{-0.0016398} \text {. }
$$

However, the regression analysis for such a relationship yields poor statistical confidence. Little variation from flight to flight in these relationships was detected.

The regression analysis for columnar crystals for the entire EMERALD database, a total of 3965 images, shows that $A_{\mathrm{r}}$ tended to values between 0.38 and 0.43 for large crystal sizes with an intercept varying from 0.57 to 0.73 for the smallest crystals detectable by the CPI (Fig. 10(c)). The parametrization, based on replicas of ice crystals obtained using collectors carried aloft by balloons during the FIRE experiment, seems to be more consistent with the higher intercept values, possibly due to the ability of the replica technique to capture and image smaller crystals more reliably than the CPI. The average nonlinear correlation, $r^{2}$, value for all flights was $0.2301 \pm 0.0752$. Interestingly the analysis for flights EM03, EM08 and EM10b yielded a higher significance level on the normal test $(>0.9)$ than the others $(<0.3)$, except for flight EM13 that appeared to be intermediate $(0.47)$. These are likely to be related to the cloud age and dynamical variation encountered but, again, the overall variation from flight to flight was not large. 
Based on the combined flight data the relationship obtained for $A_{\mathrm{r}}$ during EMERALD-1 is:

$$
A_{\mathrm{r}}=0.4115+0.2465 \exp \left(-0.0210 D_{\mathrm{pmax}}\right) \quad\left(r^{2}=0.2124\right),
$$

where $D_{\mathrm{pmax}}$ is in $\mu \mathrm{m}$. The correlations however are generally very low for $A_{\mathrm{r}}$ relationships. It is important to emphasise here that we are able to produce almost identical parametrizations with the EMERALD dataset to those previously published. Yet despite our dataset (in terms of number of ice particles imaged) being large, or larger than those used previously, the correlations for such relationships can still be very low particularly for the more complex crystal types even when confined to a single well-defined cloud type as in this case. Previous studies have not emphasized this point, and some caution is therefore suggested in the use of these relationships even for apparently simple cloud types.

\section{(a) Ice crystal habit and growth}

Ice crystal habits and distributions can show large variability in ice clouds whose temperatures are below approximately $-20^{\circ} \mathrm{C}$. In many clouds some of this variation may be attributed to variations in the ice nuclei available and the conditions under which crystal formation occurs. Recent laboratory experiments by Bailey and Hallett (2002) suggest that rosette-type crystals result from ice nuclei that share few similarities with ice in terms of crystallography structure. We observe in the EMERALD-1 dataset the now generally held picture of these midlatitude low temperature $\left(-30\right.$ to $\left.-60{ }^{\circ} \mathrm{C}\right)$ cirrus clouds, in that they are dominated by small poly-crystals and proto- or germbullet rosettes with very few pristine plate crystals found. Nucleation at cloud top is followed by subsequent growth into bullet rosettes, in some cases with modification to a combination rosette with side-plate structures, with sedimentation and/or evaporative depletion at cloud base. This picture can be substantially modified following dynamical evolution of the cirrus, with large updraught regions resulting in significant numbers of large rosette crystals at both cloud top and cloud base, which was observed in one case (EM09) shown in Fig. 2. This is consistent with laboratory studies that suggest pristine crystal types are rare in the atmosphere, and that they require a combination of low supersaturation and stable growth conditions at low temperatures to suppress the more general polycrystalline phase, unless screw dislocations are present in the forming ice structure (Bacon et al. 2003). The crystal types and sizes observed in EMERALD-1 are still consistent with current understanding of ice nucleation in cirrus (Bailey and Hallet 2002); they are the result, primarily, of homogeneously nucleated frozen water droplets that grow to more open polycrystalline types, usually rosettes; this is supported by the in situ relative-humidity observations.

The vast majority of particles in EMERALD were defined as small $\left(D_{\mathrm{p}}<100 \mu \mathrm{m}\right)$ irregular or spheroidal. However, the latter category is limited by the resolution of the CPI, and it is likely to be proto or germ polycrystal/rosettes and bullets that subsequently grow into bullet type rosettes (C2a in the categorization of Magono and Lee (1966)). The other most common types are derivatives of $\mathrm{C} 2 \mathrm{a}$ such as $\mathrm{C} 1 \mathrm{c}$ (and occasionally $\mathrm{C} 1 \mathrm{~d}$ ), $\mathrm{C} 2 \mathrm{~b}$ and $\mathrm{C} 1 \mathrm{e}$ (and occasionally $\mathrm{C} 1 \mathrm{f}$ ). Regions were also encountered, however, where S3 types were beginning to form. Very rarely, types P1a were also seen, presumably mixed to the observation level from warmer regions; examples of these are also shown in Fig. 7. 

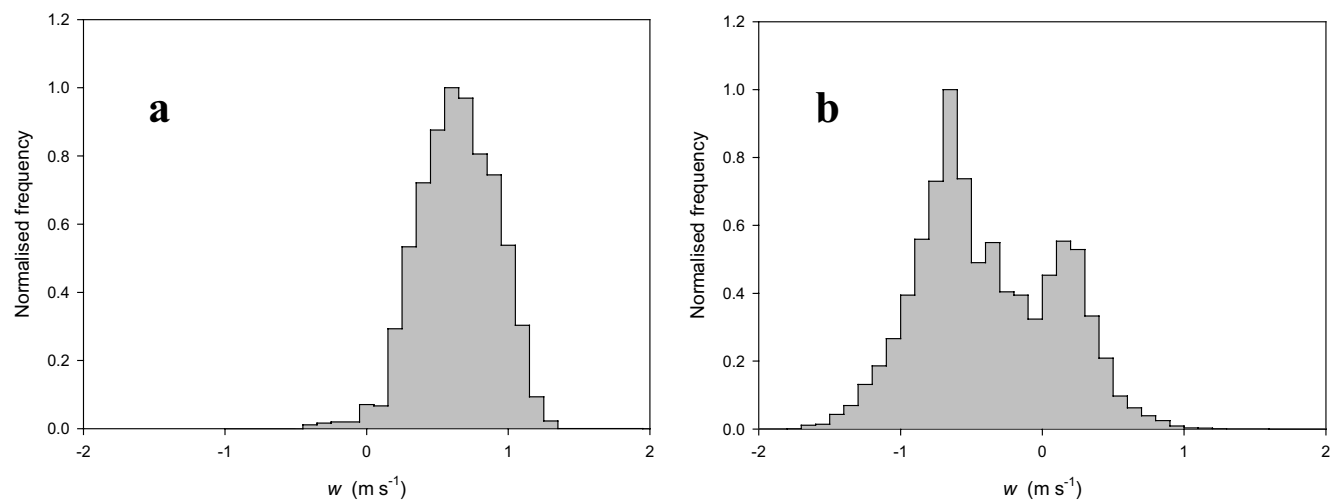

Figure 11. Normalized frequency distributions of vertical velocity, $w\left(\mathrm{~m} \mathrm{~s}^{-1}\right)$, from in-cloud periods observed in EMERALD-1 flights: (a) EM09, and (b) EM11.

\section{TURBULENCE STATISTICS AND ICE CRYSTAL EVOLUTION IN FALL STREAKS}

The lidar data collected by the King Air aircraft that underflew each cirrus cloud showed that significant structure could occur on multiple scales within these cloud types. The case of flight EM09 (see Fig. 2) is an example of the large dynamical variation that can be encountered with significant large-scale wave-induced ascent. Large variation between cloud base and cloud top occurred throughout the flight, with significant fall streaks observed in some regions in which evaporating bullet rosette crystal forms were observed. Somewhat atypical of the other flights, significant concentrations of bullet rosettes were observed near cloud top in EM09. In general, however, turbulent velocities observed in most of the cirrus cloud penetrations varied over a relatively small range, typically less than $\pm 0.5-1.0 \mathrm{~m} \mathrm{~s}^{-1}$. For example, in EM09 the range of vertical velocities detected during in-cloud legs was only -0.93 to $+1.52 \mathrm{~m} \mathrm{~s}^{-1}$ with a mean of $+0.59 \pm 0.27 \mathrm{~m} \mathrm{~s}^{-1}$ sample standard deviation. Flight EM09 turbulence statistics typically showed a negative skewness factor $(-0.24$, Fig. 11(a)). Interestingly, flight EM11 (Fig. 11(b)) exhibits a bimodal vertical velocity distribution with significant demarcation between updraught and downdraught regions as a result of encountering more vigorous fall-streak regions, but again the range of velocities was relatively narrow, -2.13 to $+1.50 \mathrm{~m} \mathrm{~s}^{-1}$, with a mean of $-0.38 \pm 0.49 \mathrm{~m} \mathrm{~s}^{-1}$ sample standard deviation.

Quite often regions of significant updraughts appeared to be correlated with the presence of very high concentrations of small ice crystals. The increased concentrations of very large bullet rosette crystals, either close to the top of such updraught regions as in EM09 (Fig. 2) or within downdraughts, supports the dynamical picture presented above. These case-studies will be described in greater detail in subsequent presentations; however, the time-scales associated with these velocities over the vertical extent of the cloud will provide useful initiation fields for microphysical-model comparisons. Although the time-scales for crystal growth and evolution are difficult to follow within cirrus using in situ measurements, a typical example is shown in Fig. 12 which gives the particle-size spectra obtained from repeated penetration of a fall streak observed during EM09. The spectra are from the top, middle and lower regions of a fall streak identified by the lidar (there were no FSSP data for the lower region). There is evidence of aggregation of ice crystals as they reach the middle region of the cloud followed by some evaporation. Again, these will be described in greater detail in subsequent papers. 


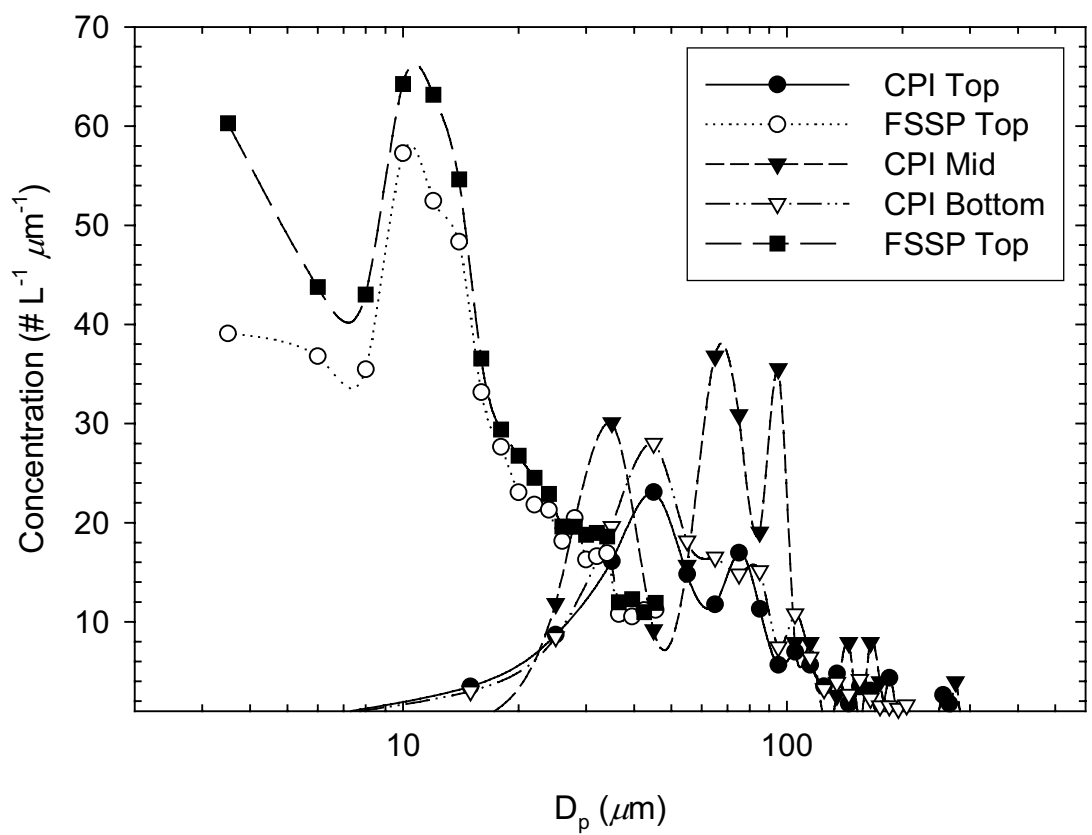

Figure 12. Evolution of particle-size distribution and habit within one fall-streak region, from EMERALD-1 flight EM09. See text for details.

\section{CONCLUSIONS}

Observations of midlatitude cirrus microphysics and dynamics have been presented and the evolution of ice microphysical parameters investigated. At temperatures below $-37^{\circ} \mathrm{C}$ homogeneous nucleation is likely to be the dominant mode of freezing of supercooled water droplets. If water supersaturation regions exist, or even if conditions are slightly below saturation at low temperatures (Bailey and Hallet 2004), then ice crystal formation is likely to be due to the activation of cloud condensation nuclei (CCN) to form solution droplets that then freeze homogeneously. The subsequent growth of these particles results in the commonly observed characteristic bullet rosette crystals forming on the frozen droplet core. Examination of ice crystal images showed that quite often the small ice crystals which were classified as irregular were very likely to have been germ or proto bullet rosettes, as a continuous range of rosette branch dimensions is observed which consistently overlaps the irregular particle concentrations at the smallest size range. This then is the most likely sequence of events in such clouds where regions with relatively large updraughts, having large numbers of these small ice crystals controlled by the hygroscopic/hydrophilic aerosol population, will be observed. These very high concentrations were observed in several EMERALD-1 case-studies both in updraught and downdraught regions. Elsewhere regions with lower vertical velocities were detected with ice supersaturation but which were unsaturated with respect to water. This will result in the formation of ice crystals on ice deposition or immersion nuclei. This process can be efficient enough to prevent water saturation from occurring in these regions and hence deposition nucleation is dominant. In these regions smaller numbers of larger pristine ice crystals are found. (However, one must be careful with such interpretations, as the supersaturation measured with respect to ice may be significantly higher at the crystal surface.) The EMERALD-1 database suggests 
these latter regions are relatively rare, with hygroscopic aerosol controlled homogeneous nucleation dominating. In general the mean ice crystal size detected fell within a narrow size range, typically 70-90 $\mu \mathrm{m}$, and average cloud concentrations ranged from 200$1200 \mathrm{~L}^{-1}$ with a mean for all clouds of $618 \mathrm{~L}^{-1}$. However, often localized regions were detected with extremely high maximum concentrations, up to $20000-30000 \mathrm{~L}^{-1}$ as has been reported elsewhere. These concentrations are likely to be underestimates, as is suggested by the FSSP measurements, due to the limitations of the CPI sample volume for small particles.

Since the median crystal size based on population distributions is very small, it should be possible to test these observations using current microphysical cloud-model descriptions of cirrus ice growth mechanisms. Typical first order approaches generally do not accurately replicate the high concentrations observed in cirrus. However, a crucial observation, missing in most studies of this type, is the $\mathrm{CCN}$ or hygroscopic aerosol concentration that is currently used to tune such models once they are initiated using observed updraught velocity, temperature and relative humidity. Lack of high quality $\mathrm{CCN} /$ hygroscopic aerosol measurements is currently hampering closure in such models.

Ice crystal area ratios $\left(A_{\mathrm{r}}\right)$ were also determined and presented for columnar, plate and bullet-rosette crystal habits. The variation of $A_{\mathrm{r}}$ with crystal dimension showed good agreement with that reported from previous studies, and showed little variation from flight to flight in general. However, it should be cautioned that the $A_{\mathrm{r}}$ versus size parametrizations obtained, although showing relatively little variation from flight to flight, depending on ambient concentrations, are generally of rather low statistical correlation, thus caution in their use is advised in general. Despite this, the overall agreement with values reported by previous studies is encouraging.

The average trends in ice crystal habit, size and concentrations when segregated as a function of temperature are similar to those reported from recent cirrus studies, and are consistent with the nucleation and growth scheme described. However, our measurements show that even supposedly simple frontal cirrus can exhibit significant deviation from this picture due to dynamical mixing, one example of which is highlighted by differences between the average frequency distribution for vertical velocity for flights EM09 and EM11 (Fig. 11).

The EMERALD database, in combining high-resolution in situ turbulence and ice microphysical data with vertical cloud structure from lidar, will allow more detailed explicit and parametrized model studies of cirrus evolution to be undertaken; these will be reported in future work.

\section{ACKNOWLEDGEMENTS}

We would like to gratefully acknowledge the ARA team at Flinders Field: the pilots of the Egret and King Air, Captains Noel Roediger and Gabriel Kalotay, the ARA technical staff, Mr Rudi Gaissmaier, Graham Wilkins and the rest of the ARA technical staff for King Air operations, and the secretarial staff led by Ms. Rachel Urbon, all of whom contrived to provide a wonderfully efficient and friendly operating environment. We would also like to thank Paul Lawson, Brad Baker and their technical staff at SPEC Inc. for their assistance with the CPI, their ability to respond so willingly and rapidly to emergency requests is a rare thing in today's commercial world. Dr Paul Field of the UK Met Office also provided us with useful and insightful comments. We would like to thank our funding agent the UK National Environment Research Council (NERC). Mr Paul Connolly is in receipt of a NERC studentship. 
Bacon, N. J., Baker, M. B. and Swanson, B. D.

Bailey, M. and Hallett, J.

2002

2004

Baumgardner, D., Strapp, J. W. and Dye, J. E.

Connolly, P. J., Field, P. R., Möhler, O., Büttner, S., Saathoff, H., Heymsfield, A. J., Gallagher, M. W. and Choularton, T. W.

Cook, C., Whiteway, J., Choularton, T. W., Gallagher, M., Bower, K., Flynn, M., Green, P., Brusen, R. and Hacker, J.

Field, P. R., Wood, R., Hirst, E., Greenaway, R., Kaye, P., Brown, P. R. A. and Smith, J. A.

Gardiner, B. A. and Hallett, J.

Gayet, J.-F., Auriol, F., Minikin, A., Ström, J., Seifert, M., Krejci, R., Petzold, A., Febvre, G. and Schumann, U. Hacker, J. M. and Crawford, T. L.

Heymsfield, A. J.

Heymsfield, A. J. and Miloshevich, L. M.

1985

Ivanova, D., Mitchell, D. L., Arnott, W. P. and Poellot, M.

Kajikawa, M. and Heymsfield, A. J. 1989

Knollenberg, R. G.

Korolev, A. V.

1998

Korolev, A. V., Strapp, J. W. and Isaac, G. A.

\section{REFERENCES}

Initial stages in the morphological evolution of vapor grown ice crystals: A laboratory investigation. Q. J. R. Meteorol. Soc., 129, 1903-1927

Nucleation, growth and habit distribution of cirrus type crystals under controlled laboratory conditions. Q. J. R. Meteorol. Soc., 128, 1461-1484

'Further analysis and improvements of ice crystal mass-size relationship'. Pp. 76 in Proceedings of the 11th AMS conference on cloud physics 3-7 June 2002, Ogden, USA. American Meteorological Society, Boston, USA

Growth rates and habits of ice crystals between $-20{ }^{\circ} \mathrm{C}$ and $-70{ }^{\circ} \mathrm{C}$. J. Atmos. Sci., 61, 514-544

Evaluation of the forward scattering spectrometer probe. II: Corrections for coincidence and dead-time losses. J. Atmos. Oceanic. Technol., 2, 626-632

'Simulations of ice crystal nucleation and growth: Results from the AID Cloud expansion chamber'. Pp. 43-46 in Proceedings of the 14th international conference on clouds and precipitation, Bologna, Italy, 18-23 July 2004. WMO, Geneva, Switzerland

'Anatomy of a cirrus cloud'. Geophysical Research Abstracts, Vol. 5, 06155 Proceedings of the European Geophysical Society, Nice, April 2003

Ice particle interarrival times measured with a fast FSSP. J. Atmos. Oceanic Technol., 20, 249-261

Degradation of in-cloud forward scattering spectrometer probe measurements in the presence of ice particles. J. Atmos. Oceanic. Technol., 2, 171-180

Quantitative measurement of the microphysical and optical properties of cirrus clouds with four different in situ probes: Evidence of small ice crystals. Geophys. Res. Lett. 29(24), doi: 10.1029/2001GL014342 (AGU)

The BAT-probe: The ultimate tool to measure turbulence from any kind of aircraft (or sailplane). J. Tech. Soaring, XXIII:2, 4346

1972 Ice crystal terminal velocities. J. Atmos. Sci., 29, 1348-1357

1986 Ice particle evolution in the anvil of a severe thunderstorm during CCOPE. J. Atmos. Sci., 43, 2463-2478

1995 Relative humidity and temperature influences on cirrus formation and evolution: Observations from wave clouds and FIRE-II. J. Atmos. Sci., 52, 4302-4326

2003 Parameterizations for the cross-sectional area and extinction of cirrus and stratiform ice cloud particles. J. Atmos. Sci., 60, 936-956

2001 A GCM parameterisation for bimodal size spectra and ice mass removal rates in mid-latitude cirrus clouds. Atmos. Res., 59, $89-113$

Aggregation of ice crystals in cirrus. J. Atmos. Sci., 46, 31083121

Techniques for probing cloud microstructure. Pp. 15-19 in: Clouds: Their formation, optical properties and effects. Eds. P. V. Hobbs and A. Deepak. Academic Press, San Diego, USA

'About a definition of liquid, mixed and ice clouds'. Pp. 325326 in Proceedings of FAA workshop on mixed phase and glaciated icing conditions, 2-3 December 1998. Federal Aviation Authority, Atlantic City, NJ, USA

1998 Evaluation of the accuracy of PMS optical array probes. J. Atmos. Oceanic Technol., 15, 708-720 
Korolev, A. V., Isaac, G. A., Strapp, J. W. and

Nevzorov, A. N.

Korolev, A. V., Isaac, G. A. and Hallett, J.

Lawson, R. P. and Cormack, R. H.

Lawson, R. P. and Jensen, T. L.

Lawson, R. P., Heymsfield, A. J., Aulenbach, S. M. and Jensen, T. L.

Lawson, R. P., Baker, B. A., Schmitt, C. G. and Jensen, T. L.

Lynch, D. K., Sassen, K., Star, D. and Stephens, G. L. (Eds.)

Magano, C. and Lee, C. W.

Mitchell, D. L.

Mitchell, J. F. B., Senior, C. A. and Ingram, W. J.

Rosefeld, D. and Woodley, W. L. 2000

Sassen, K.

Stephens, G. L., Tsay, S.-C., Stackhouse, P. W. Jr. and

Ström, J. Flatau, P. J.

Ulanowski, Z., Connolly, P., Flynn, M., Gallagher, M., Clarke, A. J. M. and Hessee, E.

Whiteway, J. A., Cook, C., Choularton, T., Gallagher, M., Bower, K., Figueras-Nieto, D. and Flynn, $\mathrm{M}$.

Whiteway, J., Choularton, T., Harries, J., Gallagher, M., Bower, K., Busen, R., Aspey, R., Connolly, P., Cook, C., Flynn, M., Hacker, J., Murray, J. and Straine, G.

2004 1999a In situ measurements of effective diameter and effective droplet number concentration. J. Geophys. Res., 104, 3993-4003

1999b Ice particle habits in Arctic clouds. Geophys. Res. Lett., 26(9), $1299-1302$

1995 Theoretical design and preliminary tests of two new particle spectrometers for cloud microphysics research. Atmos. Res., 35, 315-348

1998 'Improved microphysical observations in mixed phase clouds'. Pp. 451-454 in Proceedings of the American Meteorological Society, Boston, USA

1998 Shapes, sizes, and light-scattering properties of ice crystals in cirrus and a persistent contrail during SUCCESS. Geophys. Res. Lett., 25, 1331-1334

2002 An overview of microphysical properties of arctic clouds observed in May and July 1998 during FIRE ACE. J. Geophys. Res., 106, 14989-15014

2002 Cirrus. Oxford University Press, Oxford, UK

1966 Meteorological classification of natural snow crystals. J. Fac. Sci. Hokkaido, 2, 321-335

1996 Use of mass- and area-dimensional power laws for determining precipitation particle terminal velocities. J. Atmos. Sci., 53, 1710-1723

1989 CO2 and climate: A missing feedback. Nature, 341, 132-134

2000 Deep convective clouds with sustained supercooled liquid water down to $-37.5^{\circ} \mathrm{C}$. Nature, $\mathbf{4 0 5}, 440-442$

1985 Highly supercooled cirrus cloud water: Confirmation and climatic implications. Science, 227, 411-413

1990 The relevance of the microphysical and radiative properties of cirrus clouds to climate and climate feedback. J. Atmos. Sci., 47, 1742-1753

2002 'Interhemispheric differences in cirrus properties from anthropogenic emissions'. INCA Final report. EU contract No. EVK2-1999-00039

'Using ice crystal analogues to validate cloud ice parameter retrievals from the CPI ice spectrometer data'. Pp. 1175-1178 in Proceedings of the ICCP 4th international conference on clouds and precipitation, Bologna, Italy, 18-23 July 2004

2002 'Results from the EMERALD airborne cirrus measurement campaign'. In Proceedings of European Geophysical Society ILCS (lidar conference) meeting, Nice, April 2002

2003 'Airborne measurements in the cirrus outflow from tropical convection'. Proceedings of the EGS-AGU-EUG joint assembly, Nice, April 2003 